\title{
The Potential of Stem Cells in the Treatment of Cardiovascular Diseases
}

\author{
Aurora Bernal • Beatriz G. Gálvez
}

Published online: 15 August 2013

(C) The Author(s) 2013. This article is published with open access at Springerlink.com

\begin{abstract}
Although the adult mammalian heart was once believed to be a post-mitotic organ without any capacity for regeneration, recent findings have challenged this dogma. A modified view assigns to the mammalian heart a measurable capacity for regeneration throughout life. The ultimate goals of the cardiac regeneration field have been pursued by multiple strategies, including understanding the developmental biology of cardiomyocytes and cardiac stem and progenitor cells, applying chemical genetics, and engineering biomaterials and delivery methods that facilitate cell transplantation. Successful stimulation of endogenous regenerative capacity in injured adult mammalian hearts can benefit from studies of natural cardiac regeneration.
\end{abstract}

Keywords Cardiac stem cells · Cardiac progenitors · Cardiomyocytes $\cdot$ Cardiac cell therapy

\section{Introduction \\ Clinical Imperative}

Acute myocardial infarction (MI), typically caused by coronary artery occlusion and ischemia, is a leading cause of death worldwide $[1,2]$. MI leads to cardiomyocytes (CMCs) apoptosis and death [3] and causes an irreversible loss of myocardium followed by the replacement of scar tissue [4]. MI causes significant amounts of deaths but a reduction in myocytes number and cardiac pump dysfunction are marked in many of the survivors [3].

The central cellular mechanism underlying the development of myocardial dysfunction is a decrease in the number

\footnotetext{
A. Bernal • B. G. Gálvez $(\bowtie)$

Centro Nacional de Investigaciones Cardiovasculares (CNIC),

C/Melchor Fernández Almagro, 3, 28029 Madrid, Spain

e-mail: bgonzalez@cnic.es
}

of viable $\mathrm{CMC}$, secondary to either acute ischemic injury or chronic apoptosis, and an inability of remaining CMCs to compensate for this loss through a hypertrophic response [5-7]. Heart failure after infarction occurs as a result of a process known as myocardial remodelling. This process is characterized by a myocyte apoptosis, CMCs replacement by fibrous tissue deposition in the ventricular wall, progressive expansion of the initial infarct area, and dilation of the left ventricular lumen. Another integral component of the remodelling process appears to be the development of neoangiogenesis within the myocardial infarct scar, a process requiring activation of latent collagenase and other proteinases [8].

For those enough to survive MI, necrotic myocardium that might represent one billion lost CMCs provokes an inflammatory response and recruitment of local fibroblasts. In the next few weeks, a large, collagen-rich scar tissue forms in its place. The scar provides a rapid solution; however, it is a not contractile tissue. Indeed, cardiac scarring, though to be irreversible, weakens the heart while also increasing susceptibility to compensatory pathology, aneurysm, additional MI events, and organ failure [1].

The endocardium stands out among all the heart tissues, as it shows the earliest responses yet seen after cardiac injury. Within an hour of local injury, endocardial cells throughout the heart take on a rounded morphology and show detachment from underlying myofibers. Concomitant with these morphological changes, endocardial cells induce the expression of developmental marker genes, raldh2 and heg, in an organ-wide manner by $3 \mathrm{~h}$ post-injury [9]. Interestingly, this activation does not occur in the vascular endothelium, suggesting a distinct role of the endocardial endothelium in this response. Similarly, embryonic epicardial markers tbx18 and raldh2 are induced in adult epicardial cells as early as 1 day after injury, and become detectable around the periphery of the entire heart by 3 days post trauma [10]. In the myocardium, GATA4 regulatory sequences are activated in 
ventricular CMCs located in the subepicardial compact layer of the entire ventricle by 7 days post-injury, before this signature localizes to regenerating CMCs. At different time courses depending on the cell type, these injury-activated expression signatures disappear globally and localize to the injury site, where they aid or indicate cardiac muscle regeneration, as described later [11].

Many scientists and clinicians believe that MI patients represent the greatest potential beneficiaries from regenerative medicine, which aims to restore functional tissue through stem and progenitor cell manipulation. Indeed, the development of therapies that can facilitate survival or regenerative replacement of destroyed myocardium would be of enormous social and economic impact. Cardiac regeneration is a multidisciplinary research area, focus on exploring the physiology, stem cell and developmental biology, and biomaterial and tissue engineering as possible tools, with the ultimate goal of achieving regenerative medicine that can prevent or reverse heart failure. Given the poor cardiac regenerative capacity of adult mammals, considerable efforts have been made in attempts to somehow stimulate endogenous or transplanted cellular sources to create new muscle within the environment of an injured heart [1].

\section{Heart's Regenerative Capacity}

Heart as terminally defined organ The concept of the heart as a terminally differentiated organ unable to replace working myocytes has been at the center of cardiovascular research and therapeutic developments for the past 50 years [12]. In the past three decades, the focus of molecular cardiology has been the identification of the signaling pathways regulating the activation and depression of genes implicated in the hypertrophic reaction of myocytes in physiologic development and aging or following abnormal pathologic states [13]. In experiments performed, adult mammals were probed for the capacity to regenerate cardiac muscle after several models of injury, including MI, burning, freezing, mechanical injury, and chemical injury [14]. Although CMCs are mononucleated and proliferative in the fetal mammalian heart, shortly after birth the vast majority of CMCs DNA replication occurs without cytokinesis or karyokinesis. Thus, most CMCs are binucleated with diploid nuclei in the adult mouse heart, and mononucleated with polyploid nuclei in the adult human heart [15]. After this postnatal switch, it is rare for $\mathrm{CMCs}$ to enter the cell cycle. It was agreed that the key limitation to cardiac muscle regeneration is likely to be the poor ability of adult mammalian CMCs to enter the cell cycle and undergo division [1].

The dogma introduced was that the heart survives and exerts its function until death of the organism with the same or lower number of cells that are present at birth moment. Accordingly, ventricular myocytes in humans are terminally differentiated cells, and their lifespan corresponds to that of the individual. The number of myocytes reaches an adult value a few months after birth [16]. However, this assumption contradicts the concept of cellular aging and apoptotic cell death as well as the logic of a slow turnover of cells with time in the heart. Myocyte death occurring with age and the chronic loss of cells in the absence of myocyte multiplication would result in the disappearance of the entire organ over a period of a few decades in spite of the obvious facts and findings documenting activation of the cycle machinery, karyokinesis, and cytokinesis in a subpopulation of myocytes the resistance to a shift in paradigm has been enormous $[17,18]$.

Static homeostasis vs. heart self-renewal Several reports have provided evidence that myocytes die and that new ones are constantly being formed in the heart at all ages in animals and humans [16]. Both processes are markedly enhanced in the presence of disease states, and the imbalance between cell growth and cell death is a critical determinant of cardiac decompensation and its evolution to congestive heart failure and death of the organism.

Evidence challenging the accepted heart-concept has been slowly accumulating $[14,17]$. In the past few years, it has been documented the existence of cycling ventricular myocytes in the normal and pathologic adult mammalian heart of several species, including humans [17, 19]. Early observations suggested that injury may influence the propensity for adult mammalian CMCs proliferation [14] estimated that $22 \%$ of CMCs in the human heart are renewed annually [20]. With their calculations, $13 \%$ of endothelial cells (ECs) and $20 \%$ of fibroblasts undergo turnover each year in the heart, suggesting that CMCs have the highest renewal capacity among cardiac cell types examined in the study. Overall, these data suggest that the mammalian heart possesses a measurable capacity for renewal. It is not yet clear whether $\mathrm{CMCs}$ are renewed through differentiation from a stem/progenitor population or through cell division by existing CMCs [1].

Although these data provided an alternative view of cardiac homeostasis, they also raised some questions because it required reconciliation of two apparent contradictory bodies of evidence: the well-documented irreversible withdrawal of cardiac myocytes from the cell cycle soon after birth on one hand, and the presence of cycling myocytes undergoing mitosis and cytokinesis on the other one. The results raised the question as to the origin of the cycling myocytes and their dramatic increase in response to an acute work overload [17].

Heart as a dynamic organ Several lines of evidence have suggested that the heart is a dynamic organ: myocyterestricted overexpression of IGF1 [16], telomerase [21], cyclin D [22], bcl-2 [23] or cdk2 [24] is associated with an 
increase in the number of CMCs and higher tolerance to pathologic conditions. Some groups report that the number of myocytes in the myocardium increases from birth to adulthood, and BrdU, MCM5, Ki67, or thymidine labeling of myocytes persists throughout life in rodents, indicating a continuous generation of parenchymal cells [16]. It has been also suggested the dynamism of CMCs showing the regenerated myocardium was constituted by BrdU positive small myocytes, capillaries, and arterioles that appeared to mature over time. The myocytes expressed cardiac myosin heavy chain, $\alpha$-sarcomeric actin ( $\alpha \mathrm{SA}), \alpha$-cardiac actinin, ncadherin (n-cadh) and connexin 43 (Conn43) [17]. On the other hand it has been assumed that proliferation by resident CMCs is the primary source mechanism for regeneration of the adult zebra fish or neonatal mouse heart. While the nonmuscle injury environment likely contributes, intrinsic mechanisms must also underlie their regenerative capacity. CMC dedifferentiation is typically characterized by reduction of sarcomere structures and expression of fetal gene markers, and appears to be a shared mechanism associated with cardiac muscle regeneration [1].

Today, it is assumed that myocyte regeneration occurs in humans and animals after infarction [6, 17], after prolonged pressure overload [18], and in the senescent decompensated heart [16].

\section{Stem Cells for Cardiac Cell Therapy}

Myocardial repair requires the formation of myocytes and coronary vessels, and a cell already committed to the myocyte lineage cannot accomplish it. Myocytes would not grow or survive in the absence of vessels. Similarly, the utilization of cells capable of creating exclusively coronary vessels cannot result in significant tissue regeneration. In spite of an unsubstantiated and rather popular belief [25], vessels alone do not generate force in an akinetic scarred region of the ventricular wall. Myocardial regeneration needs the administration of a more primitive cell that is multipotent and can differentiate into the main cardiac cell lineages: myocytes, vascular smooth muscle cells (SMCs) and ECs [16].

It has been a long-term goal to find a method to increase the number of CMCs or to recover CMCs function after myocardial injury. Widely used candidate stem cells in experimental animal models have been embryonic stem cells (ESCs), induced pluripotent stem (iPS) cells, and somatic stem cells from various adult tissues as bone marrow-derived mesenchymal stem cells (BMSCs) and heart-derived stem cells [3].

The immune regulatory properties of several populations such as MSCs, but also more recently other types of committed stem cells (c-kit, cardiac or lung SCs) have been demonstrated to be an important advantage for their use in cell therapy [26].

Stem cell-based therapy holds tremendous promise in the treatment of myocardial ischemia due to their regeneration potential [4]. However, cell therapy protocols, using different types of stem cells, have achieved partial and variable success $[2,6,17]$. That is the reason why is necessary to understand potential features of different cell sources to develop a more efficient tool for cardiac cell therapy.

Embryonic and induced pluripotent stem cells (ESCs \& iPS) Embryonic stem cells (ESCs), described on humans by Thompson [27] are the prototypical stem cells. They unambiguously fulfill all requirements of stem cells: clonality, self renewal and multipotentiality [28]. ES are able to differentiate into any adult cells and can efficiently generate both functional beating mature CMCs and vasculature; however, their therapeutic use is hampered by associated teratoma formation and the need for an allogeneic source [29].

Pathways involved on ES-cell differentiation and for heart embryonic development increases, ESCs differentiation could be controlled. Methods to limit teratoma formation include genetic selection of differentiated ES cells, or differentiation of ES cells in vitro into CMCs or ECs before injection [29]; for example, it has been reported that tumour-necrosis factor promotes the differentiation of ES cells into CMCs [30].

Because ESCs are able to differentiate efficiently into a cardiovascular cell types, their use may solve some problems related with low cell engraftment and lower differentiation into a cardiovascular cell types. From ESCs limitations and taking into account these ESCs features, iPS cells were develop as a new cell type technology.

iPS cells technology have been developed to avoid ESCassociated problems/minor points. iPS cells have been generated from a variety of human somatic and adult mice cells by ectopic expression of a small number of defined transcription factors, such as Oct3/4, Sox2, Kfl4 [31, 32]. These cells were demonstrated to be indistinguishable from ES cells in terms of DNA methylation, global gene expression, and more importantly, the development of viable chimaeras after being introduced into mouse blastocysts. All these studies imply that iPS cells can be used as pluripotent starting material to substitute ES cells and generate lineage specific, therapeutic cell types. In addition, the use of genetically identical, patient-specific iPS cells derived from patients' own somatic cells can overcome immunological concerns associated with allogeneic or xenogeneic donor cells in clinical applications. Recent efforts have focused on adapting ES cell-differentiation methods to iPS cells demonstrating that iPS cells can be differentiated into cells of the hematopoietic lineage [33]. 
Bone marrow-derived mesenchymal stem cells (BMSCs) BMSC stem cells derived from adult tissue and they are identified as an adherent, fibroblast-like population. Although originally MSC were isolated from bone marrow, these cells have been isolated from many other tissues as skeletal muscle, adipose tissue, umbilical cord, amniotic fluid, lung, etc. MSC are able to differentiate to osteoblasts, adipocytes as well as chondrocytes. It has been reported the capacity of MSC to secrete different factors that promote tissue, repair in a paracrine way, stimulating cell proliferation and tissue-resident progenitor differentiation and decreasing immune response [34].

BMSC like hematopoietic stem cells [35] and mesenchymal stem cells [36] were thought to differentiate to cardiac muscle and contribute to functional recovery after MI. BMCs were injected in the border zone of a myocardial infarct or were mobilized systemically into the circulation with cytokines. Both interventions led to the repair of the injured tissue and the formation of functionally competent myocardium in mice $[35,37]$.

It has been also proposed the fusion of BMCs with CMCs as a new alternative mechanism. However, although occasional examples have been reported in the normal heart, cellular fusion between BMCs with $\mathrm{CMC}$ remains an in vitro phenomenon [38]. Therefore, that was assumed at that moment was the several million myocytes formed in the infarcted mouse heart by injection of BMCs are the product of $\mathrm{BMC}$ differentiation and not cell fusion [35, 39].

However, results from subsequent studies indicate that these cell types may contribute to cardiac muscle survival/ repair by indirect paracrine mechanisms improving myocardial function after ischemic injury through the release of protective factors [4, 40-42], as opposed to direct differentiation into myocardium [40].

Heart resident stem cells Until recently [43], the heart was originally thought to be entirely composed of terminally differentiated CMCs that withdrew from the cell cycle shortly during the perinatal period as well as the mammalian heart is a terminal post-mitotic organ without self regeneration capacity after myocardial injury [44], and that cardiac injury caused permanent myocardial loss coupled with cardiac dysfunction [45].

However, this paradigm has been challenged by the work of Beltrami and colleagues [17] who for the first time, discovered specialized cells within the heart tissue expressing stem cell markers (ckit, Scal and Mdr1). These cells, known as adult cardiac stem cells (CSCs), show the stem cell criteria including self-renewal, clonogenicity, and multipotency [44]. Accumulating studies have recently demonstrated that adult hearts contain a small number of cells expressing stem cell markers (Sca1, ckit, etc.) [2, 17,
$46,47]$. So far, several research groups have reported the isolation of cardiac stem like cells from various species such as mice, rat, dog, pigs and human hearts based on the cell surface antigens, stem cell antigen 1 (Sca1 [2, 46-50], Abcg2 [51, 52], and ckit [6, 7, 17].

It has been described at least 7 different types of CSCs, including the pan-stem cell marker ckit+cells [17, 53, 54]; the cell surface marker stem cell antigen Sca1+cells [2, 48]; the transcription factor Isl1+ cells [5, 55], the cardiac side population that possess physiological properties to efflux fluorescent dye (Abcg2+/Mdr1+) [52, 56, 57], the cardiac mesoangioblasts $[47,50]$, the cardiosphere-derived stem cells (ckit+/Sca1+/Flk1+) [7, 58], and the epicardial progenitors [59, 60] have been isolated and characterized from hearts by different laboratories [54, 61-63].

Different CSC populations share and differ on some surface markers expression. The Abcg2 or side population cells also express Scal and ckit, yet the latter is described as being low $[51,52]$. Also, some of the isolated Sca1+ cells are also positive for ckit $[48,64,65]$ and likewise for the ckit+cells [7]. However, some Sca1+ cells are negative for ckit [2]. These differences and similarities in phenotype bring into question whether they are all exclusively different or actually of the same population of cell yet selected and identified at different physiological states [66-68]. It could be that there exists a single CSC that expresses all of the markers identified depending on its developmental transition pathway. Although, the origin and the function of these cells remain unclear, different putative adult CSCs most likely represent different developmental and/or physiological stages of a unique CSC population in the adult mammalian heart [69, $70]$.

Besides the characteristic surface markers, several CSC express some transcription factors such as GATA4, Nkx2.5 and Mef2, together with the small amounts of sarcomeric proteins in the cytoplasm. This phenotype strongly suggests that these cells clusters represent amplifying myogenic precursors and/or progenitors derived from the activation of a more-primitive stem cell. The expression of transcription factors associated with early cardiac development, such as GATA4 and Nkx2.5 and particularly, the expression of cardiac-specific sarcomeric proteins by some of the cells in each cluster, is strong evidence in support of their cardiac myogenic potential and, most likely, of their cardiac myogenic fate suggesting that CSC might be cardiac precommitment [17].

CSCs are stored at niches and the niches control the physiological turnover of cardiac cells and the growth, migration, and commitment of CSCs that leave the niches to replace dying cells within the myocardium throughout life [18]. CSCs are involved in the renewal of myocytes, ECs, SMCs a fibroblast located on the heart [6, 17, 46, 47, 54, 66, 71]. 
The origin of these primitive cells, their presence in normal and pathological hearts, together with the identification of some of them having initiated the CMCs gene expression program, is suggestive that they might be true CSCs that give rise to the cycling myocytes detected in the adult heart. If this were the case, their manipulation might provide the opportunity to stimulate myocardial regeneration with endogenous cells. Cells with the characteristics of myogenic stem and progenitor cells are present in the adult myocardium. The identification of these cells opens the possibility that they might be coached in vivo to home within the damaged myocardium, subsequently promoting functional cardiac repair without the need of introducing exogenous cells [17].

\section{Heart-derived Progenitor and Stem Cells Populations}

ckit + Cardiac Stem Cells

ckit + cardiac stem cells The ckit + /Lin- cells represent one of the major CSC populations found in the heart [63]. As CSC has been identified and characterized in the heart of rats [17], mice $[2,48,51]$ and dogs [6], ckit + CSCs have been extensively examined, in terms of stem cell characteristics, and consistently exhibit several in vitro characteristics that define a "stem cell" [72]; being clonogenic, self-renewing, and multipotent. Resident ckit CSCs have been found to be most abundant in hearts of neonates [73]. However in adult human heart, the number of ckit+cells in even lower $0.01 \%$ [54]. Not only on children but also on adults, these cells are present in highest number in the right atrial appendage [73, 74]. ckit + cells isolated from heart have been suggested to differentiate to not only endothelial and smooth muscle lineages but also to cardiac lineage after infarction [75.]

Moreover, cardiac lineage markers expression before and after differentiation process is controversial $[44,76]$. The ckit antigen, which is a tyrosine kinase receptor [75] is expressed primarily hematopoietic stem cells, but its expression disappears in cells of hematopoietic lineage after differentiation, except on mast cells. In fact, it has been recently suggested that ckit+cardiac progenitor cells isolated from human heart tissue are actually mast cells [77]. Similarly, it is unclear whether or not the ckit population is contaminated by other cells such as the cardiac fibroblasts, mast cells or hematopoietic lineage cells and whether the expression of ckit remains stable after tissue processing and long-term cell culture (Table 1).

Sandsted and colleagues report that once cardiac biopsies were dissociated, by flow cytometry it was identified two ckit cell populations based on the CD45 expression, expressed primarily in hematopoietic cells. CD45-/ ckit+population was found to co-express the endothelial progenitor marker CD34 as well as CD31. On the other hand, CD45+/ckit+cells were negative for CD34 and CD31 but expressed CD33 mast cells marker. It was also reported all of them were negative for CD133, Abcg2, Mdr1 as well as Sca1 [75]. Markers lineage expression data are even more conflicted. For instance, Anversa and colleagues reported that human ckit + cells, do not express all the cardiac lineage markers such as GATA4, Nkx2.5, Mef2c, $\alpha$-SA, $\alpha$-smooth muscle actin ( $\alpha$-SMA), CD31, and Kdr before differentiation as measured by flow cytometry; whereas $4-23 \%$ of the unfractional cell population after isolation was found to be positive for these markers $[54,55,78]$. In their recent study, they reported a similar lack of expression of cardiac lineage markers, except for Kdr, which was found to be expressed in $3 \%$ of ckit + population [78]. In contrast, Itzhaki-Alfia et al have reported that the un-fractioned adult human CSCs are positive for GATA $4+(60 \%)$ and cardiac $\alpha$-SA $+(60 \%)$ even before ckit purification [74]. In neonatal hearts and heart tissue from young children, however, the percentages of ckit + ranged from $5 \%-9 \%$ and only small percentage (1 \% to $3 \%$ ) of ckit + cells were double positive for $\mathrm{Nkx} 2.5+[44,73]$.

Because ckit+/Lin- cells are pre-committed resident CSCs, it is likely that they exist in heart in various stages of development and therefore they express cardiac lineage markers. Published data on human support this hypothesis. During early heart development ckit + and Nkx2.5+ were coexpressed in some CSCs with relative lower levels in children 2 to 13 years [73]. In adult hearts, however, several different populations of stem cells committed to the cardiac lineage have been identified. These include (a) precommitted $\mathrm{CMCs}$ co-expressing ckit $+/ \mathrm{Nkx} 2.5+$, ckit $+/ \alpha-$ $\mathrm{SA}+, \mathrm{ckit}+/ \alpha-\mathrm{SA}+/ \mathrm{Nkx} 2.5+, \mathrm{ckit}+/ \mathrm{Mef} 2 \mathrm{c}+, \mathrm{ckit}+/ \alpha-\mathrm{SA}+/$ Mef2c + in CSC niches of tissue sections of rat [17], mouse [79], and human hearts [54, 71]; (b) pre-committed endothelial progenitors co-expressing ckit $+/ \mathrm{vWF}+$, ckit $+/ \mathrm{Kdr}+$, ckit $+/ \mathrm{vWF}+/ \mathrm{Kdr}+$; and (c) pre-committed SMCs coexpressing ckit $+/ \mathrm{Kdr}+/ \alpha-\mathrm{SMA}+$ in vascular niches of human hearts $[17,54,71]$. Identify these cells after dissociation it could be possible due to several types of pre-committed CSCs at various differentiation stages co-exist in the adult heart, as it has been suggests by some studies. However, because technical reasons, the actual number of each type of pre-committed CSCs within the entire heart has not been reported [54], although their abundance has been presumed to be low. Interestingly, Hong has reported the development of a highly sensitive and accurate method to quantify the absolute number of murine CSCs after transplantation [80].

It has been reported variable levels of ckit+expressions in cultured cells before purification and differentiation. Beltrami et al [17] found that the percentage of ckit + cell 
Table 1 Heart-derived progenitor and stem cells populations

\begin{tabular}{|c|c|c|c|c|c|c|}
\hline $\begin{array}{l}\text { Cardiac } \\
\text { progenitor }\end{array}$ & Markers & $\begin{array}{l}\text { Fate differentiation } \\
\text { potency }\end{array}$ & $\begin{array}{l}\text { Cardiac } \\
\text { differentiation }\end{array}$ & Once differentiated & In vivo outcomes & $\begin{array}{l}\text { Used on } \\
\text { clinical } \\
\text { trial }\end{array}$ \\
\hline ckit+Lin- & $\begin{array}{l}\text { ckit }+ \text { Lin- } \\
\text { CD31+ Nkx2.5+ } \\
\text { Mef2c+GATA4+ }\end{array}$ & $\begin{array}{l}\text { CMC } \\
\text { SMC } \\
\text { EC }\end{array}$ & $\begin{array}{l}\text { 5' azacytidine } \\
\text { dexamethasona }\end{array}$ & $\begin{array}{l}\mathrm{CMC} \text { markers sarcomera } \\
\text { action potential }\end{array}$ & $\begin{array}{l}\text { Improve cardiac } \\
\text { recovery and } \\
\text { functionality }\end{array}$ & + \\
\hline Sca1+ & $\begin{array}{l}\text { Sca1+ ckit- } \\
\text { CD31+ Lin- } \\
\text { Mef2c+Nkx2.5+ }\end{array}$ & $\mathrm{CMC}$ & $\begin{array}{l}5^{\prime} \text { azacytidine } \\
\text { oxytocin }\end{array}$ & CMC markers sarcomera & $\begin{array}{l}\text { Home to infarcted } \\
\text { area and } \\
\text { differentiate }\end{array}$ & - \\
\hline Isl1+ & $\begin{array}{l}\text { Is11+ Sca1- } \\
\text { Nkx2.5+ ckit- } \\
\text { GATA4+ Mef2c+ }\end{array}$ & $\begin{array}{l}\text { CMC } \\
\text { SMC } \\
\text { EC }\end{array}$ & $\begin{array}{l}\text { Neonatal CMC } \\
\text { coculture }\end{array}$ & $\begin{array}{l}\text { CMC markers sarcomera } \\
\text { action potential } \mathrm{Ca}^{2+} \\
\text { transmission }\end{array}$ & Not determined & - \\
\hline $\begin{array}{l}\text { Cardiac } \\
\text { mesoangioblasts }\end{array}$ & $\begin{array}{l}\text { Sca1+ ckit }+ \text { Is11+ } \\
\text { Nkx } 2.5+\text { GATA4+ } \\
\text { Mef } 2 c+\text { Cn } 43+\end{array}$ & $\mathrm{CMC}$ & $\begin{array}{l}\text { Neonatal CMC } \\
\text { coculture } 5^{\prime} \\
\text { azacytidine }\end{array}$ & $\begin{array}{l}\mathrm{CMC} \text { markers sarcomera } \\
\text { action potential beating }\end{array}$ & $\begin{array}{l}\text { Improve cardiac } \\
\text { recovery and } \\
\text { functionality }\end{array}$ & - \\
\hline Side populations & $\begin{array}{l}\text { Abcg2+ Bcrp1+ } \\
\text { Sca1+ ckit+ } \\
\text { Nkx2.5- Mef2c+ }\end{array}$ & $\mathrm{CMC}$ & $\begin{array}{r}\text { Adult CMC } \\
\text { coculture }\end{array}$ & $\begin{array}{l}\text { myocyte molecular and } \\
\text { functionality properties }\end{array}$ & Not determined & - \\
\hline Cardiospheres & $\begin{array}{l}\text { ckit }+ \text { Sca1+ } \\
\text { cTnT }+ \text { Cn43+ }\end{array}$ & $\begin{array}{l}\text { CMC } \\
\text { SMC } \\
\text { EC }\end{array}$ & $\begin{array}{l}\text { Neonatal CMC } \\
\text { coculture }\end{array}$ & CMC markers sarcomera & $\begin{array}{l}\text { Indirect paracrine } \\
\text { effect }\end{array}$ & - \\
\hline Epicardial cells & $\begin{array}{l}\text { ckit+ } \\
\text { WT1+ }\end{array}$ & $\begin{array}{l}\text { No diff. } \\
\text { contribution } \\
\text { to epicardial } \\
\text { lineage }\end{array}$ & - & - & $\begin{array}{l}\text { Migrate to infarcted } \\
\text { area \& differentiate } \\
\text { into cardiac progenitors }\end{array}$ & - \\
\hline
\end{tabular}

was $7-10 \%$ in cells isolated from the rat heart; but in cells isolated from the adult human right atrium, nearly 20 to $40 \%$ of the cells $[54,74]$ were found to be ckit+, similar finding described by $\mathrm{He}$ [44] that $10-40 \%$ of the cells in isolate were ckit+before purification and differentiation. Characterization of early myogenic transcription factors of CSCs isolated from human heart has shown that 60-66 \% [74] or 59-61\% [54] of the cells were GATA4+ whereas $60-61 \%$ [74] of the cells were also positive for the late cardiac marker $(\alpha-\mathrm{SA})$. As well as were found that nearly $50 \%$ of cells were positive for both ckit and GATA4. However, the abundance of ckit+cells expressing Nkx2.5, $\alpha$-SMA, and $\alpha$-SA was low [44]. D'Amario et al have suggested [78] that ckit+CSCs could be classified, based on cardiac lineage makers and their capacity for differentiation, into two groups - the "myogenic CSCs" (mCSCs) and the "vasculogenic CSCs" (vCSCs). This classification was based on their data showing that most of the mCSCs became CMCs, whereas the vCSCs differentiate primarily into endothelial and SMCs [78]. However, in their study, before differentiation, the ckit + cell population was negative for the cardiovascular markers such as GATA4, Nkx2.5, Mef2c, $\alpha$ SA, $\alpha$-SMA, CD31, and TGF- $\beta-1 R$, and only a small percent of cells $(3.3-1.1 \%)$ were positive for $\mathrm{Kdr}$, as determined by flow cytometry $[54,71,78]$. This is no consistent with the previous study using the same technique [54] or the results obtained by other investigators $[44,73,74]$. Hence, the extent of differentiation of human CSCs in situ or before in vitro differentiation remains unclear.

Cardiac lineage differentiation of ckit+/Lin- cells have been studied by various groups using either chemical reagents, such as Dexamethasone, or co-culture with neonatal or matured CMCs [61]. It has been reported that treatment with Dexamethasone results in the appearance of cardiac markers (GATA4, Nkx2.5, Mef2c, and cardiac $\alpha$-SA) in $50 \%$ of mCSCs, whereas $10-15 \%$ of the cells show smooth muscle and endothelial markers (GATA6, $\alpha$-SMA, CD31, and vWF) after differentiation [78]. On the other hand, $40 \%-50 \%$ vCSCs became positive for smooth muscle and endothelial markers (GATA6, $\alpha$-SMA, CD31, and $\mathrm{vWF}$ ), and small percents of them (10-15\%) showed positive for cardiac markers (GATA4, Nkx2.5, Mef2c, and $\alpha$-SA) after differentiation [78]. The group of Bolli shown that 5'azacytidine treatment [49], results in a majority (70\%) of ckit+cells differentiated into CMCs, but small percent (30\%) of ckit+cells became SMCs and ECs [44], demonstrating more efficient $\mathrm{CMC}$ differentiation has been reported than before [78]. 


\section{Cardiac Progenitors Isl1+}

This postnatal cardiac progenitor express LIM homeodomain transcription factor Islet1 (Isl1) [5]. Isl1 cells were reported to be a distinct population of cardiac progenitors identified in embryonic and neonatal mouse and human hearts, but their existence in the adult heart is still unclear [5]. Cardiac progenitors express high level of early cardiac specific transcription factors, such as GATA4, Mef2c, Isl1, etc [81, 82].

It has been reported that embryonic multipotent Isll cardiovascular progenitor are clonogenic as well as self-renewal and they are able to generate the major three cell types of the heart [83].

It has been suggested that the Isl1+ cells has been improperly presented as a new CSC and claimed to be important for the reconstitution of the adult damaged heart [5]. It has been known for quite some time that the Isl1 transcription factor is present in cells that are implicated in the morphogenesis of the embryonic mouse heart [84]. The homozygous deletion of Isl1 results in developmental defects of the right ventricle, atria, and outflow tract. It is surprising that Isl1+ cells have been interpreted as a distinct population of CSCs, because the expression of Isl1 corresponds to the onset of myocyte commitment; Isl1, together with GATA4, is a transcriptional activator of the myocyte transcription factor Mef2c [85]. Moreover, the expression of Isl1 in progenitor cells clustered in the niches or scattered throughout the atrial and ventricular myocardium of the adult mouse heart is, at best, extremely rare. Is $11+$ cells are restricted to the embryonic fetal heart and are no longer present at birth [86]. Similarly, Isl1+ cells have not been detected in the failing human heart, calling into question the role of these cells in cardiac pathology. Even during development, Isl1+ cells are not implicated in the formation of the left ventricle. Thus, there is no basis for the conviction that Isl1+ cells are truly CSCs or are relevant for treatment of the diseased human heart $[5,66]$.

\section{Cardiac Mesoangioblasts}

Cardiac Mesoangioblasts are vessel-associated mesenchymal stem cells that derived from embryonic dorsal aorta [47, 87], postnatal aorta [88], heart [46, 47, 50], skeletal muscle [89, 90] and are able to differentiate efficiently into a mature CMCs [47]. It can be passaged and expanded in vitro indefinitely. These studies indicate the presence of a population of stem cells with a common morphology and plasticity residing in multiple tissues, similar to mesenchymal stem cells (MSCs) and multipotent adult progenitor cells.

Cardiac mesoangioblasts are CD44+, CD34+, CD31+, ckit+, sca1+, Isl1+, Abcg2+ and CD45-. They already expressed some cardiac markers as GATA4/6, Nkx2.5, Conn43 in proliferative conditions, while they increased actinin as well as cardiac troponin in differentiation conditions $[47,91]$.

Mesoangioblasts are able to differentiate into cell types of mesodermal origin, including smooth, skeletal, and cardiac muscle, adipocytes, bone, and blood [46, 47, 87, 88], besides into myelinating glial cells (oligodendrocytes) by ROCK inhibiting using fusimil [91], and regenerate damaged skeletal muscle in a murine model for Duchenne muscular dystrophy [90].

The central niche of this population is associated with vessels and they could be considered as a subpopulation of undifferentiated pericytes. The pericytes are the second most frequent cell type in the heart. It is, thus, somewhat remarkable that it has aroused relatively little interest in basic cardiovascular research. They were described for the first time by Carl Josef Eberth in 1871 and so named by Karl Wilhelm Zimmermann 52 years later [92] .

\section{Sca1 + Cells}

Sca1+ adult cardiac stem cells derived from mouse were isolated by the group of Schneider [2]. Sca1 is a member of the Ly6 family of antigens expressed during developing of murine T-cells, as well as in murine vascular endothelial and bronchiolar lung stem cells. A human analogue to the murine Scal antigen has not yet been identified, however Scal+ cells have previously been identified in the human heart using antibodies against the murine antigen [75]. Sca1+ progenitors seem to be a heterogeneous cell population composed of haematopoietic, mesenchymal, endothelial and cardiac progenitor cells [2].

Scal progenitors represent $2 \%$ of cardiac cells and $15 \%$ of the myocyte fraction [48]. In culture, just 3-4 \% of Sca $1+$ cells shown sarcomeric proteins, and the in vivo delivery of these leads to modest cardiomyogenesis by fusion with resident cells [48]. After oxytocin exposition, Sca1+/CD45 progenitors express cardiac transcription factors and contractile proteins organized in sarcomeric structures [93]. This cell population has the property to differentiate into CMCs after 4 weeks on a 5'azacytidine treatment [2]. In permissive media, Sca1+ progenitors are able to differentiate into SMCs, ECs, osteocytes as well as into adipocytes [66].

Sca1+ progenitors role in cardiac homeostasis has not been yet defined, but some evidences strongly suggest that myocyte turnover is almost exclusive regulated by ckit + CSCs [18].

Monolayered Sca1+ progenitor sheets located at necrotic myocardium prevent negative remodelling and improve cardiac functionality [2]. This property raised the possibility that cell transplantation acts through humoral factors release that could activate endogenous CSCs. 


\section{Cardiospheres}

Cardiospheres are progenitor cells expanding in non-adhesive substrates organized in groups forming like-sphere floating structures derived from endomyocardial biopsy specimens [58]. Cardiospheres contains a core of ckit+primitive cells, some layers of cells at different level of differentiation that express some myocyte proteins such us Conn 43 and an outer layer of mesenchymal stromal cells [66]. Cardiospheres can self-renewal and are able to differentiate into CMCs by coculture with postnatal CMCs [7].

The regenerative potential of single-cell-derived clonal ckit + cell [54] and ckit+cells sorted from cardiospheres [94] is not the same, probably due to cardiospheres are composed by a heterogeneous cell population [66]. It has been described a modified protocol [58] more efficient than the original [7] that allow to obtain higher quantity of cells for transplantation [95].

Moreover, cardiospheres are understood as a in vitro reconstitution of the complex structure of the cardiac niches identified in vivo, due to it has been described the presence of Conn43 and gap junctions between uncommitted and differentiated cells, which seem to be like a supporting cells, on cardiospheres [18].

For all of that, cardiospheres could be the ideal combination of primitive an early committed cells, but if the use of this already committed cells to myocyte, ECs and SMCs lineage is more efficient than a pure cell population of nondifferentiated cells as CSC is unknown [66].

\section{Side-populations}

Side populations are identified by their ability to expel toxic compounds and dyes through an ATP-binding cassette transporter [57], property that defines putative cardiac progenitor colony in semisolid media that are committed to myocyte lineage and are able to differentiate into a CMCs by coculture with bulk populations of cardiac cells $[51,57,66]$. Side populations are $4 \%$ of cardiac cells on foetal heart of mouse, $2 \%$ on neonatal heart and $1,2 \%$ on adults.

This cardiac population are Sca $1^{\text {high }}$, ckit $^{\text {low }}, \mathrm{CD} 34^{\text {low }}$, and $\mathrm{CD} 45^{\text {low }}$, and are defined by Bcrp1. When these populations express CD31 are located on intimal wall vessel, or located on perivascular region or on myocardial interstitium if they do not express CD31. This side population express CD29 and ncadh at the interface with myocytes and SMCs. After injury, although they generate mostly fibroblasts and SMCs, they are able to acquire the myocyte and ECs lineage. Cell side populations express P-glicoproteins, such as Abcg2, that are used to dye effluxing during postnatal developmental; and Mdr1, that is the responsible during adulthood [66].

However, only cardiac side population Sca1+, CD31show high cardiomyogenic potential [66]. It has been describe that this progenitors are able to show myocyte molecular and functional properties [96].

\section{Epicardial Progenitors}

Epicardial progenitors has been described as an alternative source of cardiac progenitor cells located at the epicardium, that derived from the proepicardium, an extracardiac transient structure, that is located near the venous pone of heart developing [97]. Epicardium is essential for the maintaining of myocardial architecture, as interstitial fibroblast derived from epicardial-derived cells physically supports the sourronding CMCs and comprise a significant proportion of the myocardial wall [95]. Proepicardial cells migrate from the proepicardium to the vascular heart tube, rising the epicardial sheet and the endothelial and smooth muscle layers of coronary vessels [66].

The epicardial covering of the heart is an interesting candidate; indeed, this tissue has been implicated as a source for CMCs during mouse cardiac development [1, 59, 98]. Proepicardial cells may not contribute directly to cardiomyogenesis but favor the expansion of myogenic precursors by paracrin effects [76]. The epicardial marker WT1 regulates the epithelial-mesenchymal transition. WT1+ progenitors travel from the proepicardium to the myocardium where they form the epicardium and electrically coupled CMC [99].

Besides, some studies reported that epicardial progenitor could mobilized after cardiac injury, and discrete signals such as retinoic acid, FGF and Thymosin b4 and Tbx 18 transcription factor, which is involved on heart development, have been reported that trigger this response [10] and also might rise to a fraction of CMC [59]. Those results suggest the potential paracrine, non-cell-autonomous pathway to drive neoangioblast following cardiac injury [95].

In the infarcted adult mouse heart, lineage-tracing experiments indicated that the epicardium does not differentiate into cardiac muscle; instead, epicardial cells contribute to the canonical epicardial lineage (epicardium, fibroblasts, SMCs, perivascular cells) [100]. In the human heart it has been identified a ckit + epicardial progenitors that are accumulated in the subepicardial space at the ischemic cardiomyopathy context [60]. This cell population migrates from the epicardium to the infarct zone, where they can proliferate and differentiate into myocyte precursors and vascular cells [101].

\section{Repair Strategies, Improvements \& Future Directions}

\section{Heart is Definitely a Non-static Organ}

The existence of myocardial stem cells capable of committing to the myogenic lineage dispels the notion of the heart as a terminally differentiated organ without self-renewal potential and provides an explanation, as well as a biologically 
satisfactory context, for the existence of the cycling myocytes. The finding of ckit + cells have already activated the myogenic program in situ, their capacity to generate a progeny of millions of myocyte when injected into the ischemic myocardium as reported here, together with the small size of the cycling myocytes in the normal, pathological, and regenerating heart indicated that these cells are the progeny of the cardiac stem or amplifying cells that have not yet reached a mature and terminally differentiated state. All data strongly suggest that throughout adult life, the stem cells characterized here regenerate the myocytes lost by the normal wear and tear and go on overdrive in response to significant myocyte loss. This, the adult heart is composed of mainly terminally differentiated parenchymal cells that do no reenter the cell cycle, is not a terminally differentiated organ because it also contains stem cells that support its regeneration [17].

\section{Repair Process}

Cellular repair process Maturation and survival of myocytes invading the infarct is dependent on the availability of oxygen in the area undergoing repair. There are two prerequisites for successful integration of cells in the ischemic region. Coronary arterioles and capillary structures have to be formed in order to bridge the dead tissue and establish communication with the normally perfused vessels of the viable myocardium. Additionally, the new vascular supply has to permeate the engrafted myocytes to preserve their survival, and favor their growth, differentiation, and contractile function. There is an orderly organization of myocytes within the myocardium and a well-defined relationship between the parenchymal cells and the capillary network. This proportion is altered with cardiac pathology, and the goal of cell therapy is the reconstitution of the heart with its physiologic and structural properties [16].

The important question is why the damaged mammalian heart fails to efficiently harness the potential of progenitor cells to create a significant amount of new cardiac muscle after injury [1]. Most regenerating myocytes were found to activate regulatory sequences of the transcription factor GATA4, a gene required for embryonic heart development [11]. Regenerating CMCs maintained this signature throughout the process, suggesting that the tissue had activated an embryonic program. This is consistent with results of transmission electron microscopy and sarcomere stains, which indicated that regenerating CMCs acquire a less organized sarcomeric structure during regeneration $[1,11,102]$.

In fact, during past few years a variety of stem cells types have been shown that under different experimental conditions have shown the capacity to give rise to cardiac myocytes. Cardiogenic potential has been demonstrated for bone BMSCs (presumibly ckit+/Lin-) cells mobilized with the systemic administration if cytokines, human mesenchymal stem cells, liver-derived stem cells, ECs, cells from the embryonic dorsal aorta, and multipotent adult progenitor cells from the bone marrow [103]. However, the efficiency for these differentiation processes in vivo seems not to be enough for overcoming the loss of CMCs after infarction and producing a successful cellular repair process.

Paracrine repair Accumulated evidence has demonstrated that cardiac and vascular differentiation of implanted cells plays a less important role in mediating cardiac protection than previously thought. However, the time period of at least several days is required for the CSCs differentiation process. Before they develop into functional CMCs for repair purposes, CSCs may secret some molecules, which are protective against myocardial injury [4]. Some studies have pointed out that stem cells mediate their beneficial effects mainly through production of paracrine factors. Stem cell secreted protective molecules have been reported to increase cell survival, reduce inflammation, promote local angiogenesis and improve myocardial function after MI [40, 42].

In fact, it is evident that paracrine factors play a major role in non-cardiac stem cell-mediated cardiac protection after MI. That treatment of CSCs prior to ischemia significantly improved myocardial function very soon after ischemia/reperfusion (I/R) [4]. These findings indicate that CSCs are capable of producing paracrine factors to mediate acute cardiac protection. It has been documented that many growth factors and cytokines derived from stem cells improve myocardial function, promote cell survival, advance ventricular remodelling and decrease tissue damage after myocardial ischemia. Among these, VEGF is a critical factor in angiogenesis and has been shown to facilitate stem cell paracrine protection in the ischemic myocardium [42]. Although the beneficial effects of SDF1 have been mainly attributable to mobilization and recruitment of stem cells into an infarcted heart, recent studies have indicated that direct delivery of SDF1 into the myocardium improved post-ischemic cardiac function within $24 \mathrm{~h}$ of injury. This favourable effect is due likely to preservation of myocardial tissue rather than through recruitment of stem cells. In fact, SDF1 has been shown to promote cell survival in a variety of cells including CMCs [104].

However, little information exists regarding the paracrine action of CSCs in cardiac protection following myocardial I/ $\mathrm{R}$ injury. In fact, CSCs are capable of producing substantial quantities of paracrine molecules [93, 105, 106]. Therefore, understanding CSC-derived paracrine action is of value to promote protective effect following myocardial ischemia. To date, although a majority of studies have shown that stem cell-secreted growth factors VEGF, HGF, IGF1 and SDF1 are able to protect the myocardium against ischemic injury, it is largely unknown what component derived from CSCs 
contributes to the improvement of cardiac function in response to myocardial I/R injury [4].

The results from an study focus on to examine effects of injecting BMSCs ckit+into the infarcted heart [107] suggest that ckit+cells somehow stimulate some degree of CMCs regeneration from an endogenous progenitor or unlabeled CMC source. The results point to paracrine effects by a still unidentified signal(s) released from the transplanted cells, a signal that can enable de novo CMC creation from a still unidentified source [1].

\section{Experimental Cardiac Cell Therapy Outcomes}

Bone marrow-derived cells (BMSCs) A subset of bonemarrow-derived haematopoietic cells was the first adult stem cells reported to differentiate into CMCs when transplanted into infarcted hearts of mice [108]. Animal studies of bonemarrow transplantation with labeled haematopoietic stem cells followed by MI revealed CMCs derived from the transplanted cells, but at an exceptionally low rate [109]. However, other studies in animals have not demonstrated differentiation of haematopoietic progenitor cells into CMCs or improvement in cardiac function [66].

On the other hand, endothelial progenitor cells, circulating BMSCs expressing ckit and Scal that show the potential to differentiate into ECs have not been shown to differentiate into CMCs in vivo, but they probably have a role in promoting angiogenesis. In addition to directly contributing to the vasculature required to deliver nutrients to new CMCs, ECs can also provide paracrine survival signals to CMCs. It has been described endothelial progenitor cells homing to ischemic tissue is mediated by SDF1, even its receptor CXCR4 has been found not only on endothelial progenitor cells but also so on mature ECs [75].

Moreover, it has been report that mesenchymal stem cells can differentiate into $\mathrm{CMCs}$ under specific conditions in vitro [110]. Differentiation into CMCs in vivo has also been observed, but at an extremely low rate. A potential advantage of mesenchymal stem cells is that they are less immunogenic than other stem cells, potentially allowing allogeneic cell therapy [111]. Mesenchymal stem cells can provide paracrine growth factor support for other cells present in injured myocardium, and this could be the major mechanism for the beneficial effects of these cells. It was sounded by a report that found these cells differentiating into bone-forming osteoblasts, instead of CMCs, in transplanted mouse hearts. These results highlight the principle that even if multipotent stem cells, such as mesenchymal stem cells, have CMC differentiation potential, preventing differentiation into other cell types is a crucial consideration [112].

Currently, no consensus exists on whether bone-marrow derived progenitor cells differentiate into CMCs in vivo. ckit+ cardiac stem cells In vitro, the ckit+/Lin- CSCs show typical stem cell properties and pluripotency, and some in vivo studies have shown that transplantation of these cells improves cardiac function in animal models of MI. However, the results obtained with these CSC are variable. Some studies report marked improvement in function, whereas other report non-significant effects on cardiac structural and function $[58$, $61,113]$.

Recently, an attractive method has been the usage of stem cells, which upon transplantation into the infarcted myocardium can repair and regenerate the lost tissue and improve cardiac function [93, 113]. Transplantation of CSCs into infarcted myocardium has improved cardiac functionality and myocardial remodelling $[2,17,93]$. Therefore, the use of CSCs seems to be promising for myocardial regeneration in the treatment of MI [4].

It has been report when ckit+/Lin- CSC are injected into an ischemic heart, these cells or their clonal progeny reconstitute well-differentiated myocardium formed by blood-carrying new vessels and myocytes with the characteristics of young cells, encompassing $70 \%$ of the ventricle [17]. ckit+CSCs differentiated into CMCs and vascular structures, generating a large volume of new regenerated myocardium, which led to restoration of cardiac function. It has been also report that the intramyocardial injection of ckit+CSCs or their local activation by growth factors results in significant reconstitution of the infarcted heart $[6,17]$. These data have been confirmed for ckit+CSCs from the human [54] and $\operatorname{dog}$ [6] heart. Therefore, the use of ckit+CSCs seems to be a promising tool for myocardial regeneration [106] [4].

Scal+ progenitors Sca1+ cardiac progenitor cells isolated from adult mice hearts can give rise to functionally beating CMCs in vitro [48] and following intravenous injection after $\mathrm{I} / \mathrm{R}$, Sca1+ cardiac progenitor cells home to the injured mouse myocardium and differentiate into $\sim 1.5 \%$ new CMCs. More limited than ckit+CSC impact on myocardial regeneration was obtained with the intravenous delivery of Sca1+ cells following I/R injury [2]. The impact on myocardial regeneration obtained through intravenous delivery of Sca1+ cells was more limited than the obtained by ckit CSCs.

Cardiac mesoangioblasts Cardiac mesoangioblasts were able to differentiate in vitro efficiently into mature CMCs [47], although their differentiation potential has been demonstrated to be dependent on the mitochondrial load [114]. It was also shown that cardiac mesoangioblasts were able to restore to a significant extent heart structure in a mouse model of coronary artery ligation although no major improvements in heart function were detected [47]. 
Cardiospheres It has been described the autologous cardiosphere-derived cells were infused into the artery associated with the infarct. The effect is likely induced by indirect mechanisms, as human cardiospheres exert beneficial effects through paracrine mechanisms when injected into immune-compromised mice after MI [105].

In summary, different kind of heart-derived progenitor and stem cell populations have shown variable results for their use on cardiac cell therapy. Whether the less impressive outcome was related to the route of administration, the animal model, or the distinct progenitor cell is unclear. Therefore, it is necessary to continue exploring all the cellular possibilities to develop an efficient tool to be used on cardiac cell therapy protocols.

\section{Mechanisms to Enhance Cardiac Cell Therapy}

Several kinds of stem cells and progenitor cells have experimentally and clinically shown benefits. However it has been also reported that the effects observed were modest.

Pre-treatment of stem cells with cytokines is a simple procedure, and inclusion of a relatively small cDNA in a viral vector is also a feasible procedure in the context of autologous cell therapy with engineered stem cells. These strategies for example represent a novel and simple method for improving the potential of stem cells to repair damaged heart and for increasing the regeneration area and could be tailored in the future to different types of stem cells in clinical cell therapy protocols. In literature, one can find different approaches to modify and improve stem cells biology and we will proceed through some of those different methodologies (Fig. 1).

microRNAs MicroRNA (miRNAs) are evolutionary conserved small noncoding RNAs encoded by introns and intergenic regions than modulate gene expression in a posttrancriptional repression by mRNA inhibition or degradation [115]. It has been reported the role played by the miRNAs on control development, tissue homeostasis, differentiation modulating, proliferation, apoptosis and several diseases [116-118]. Focusing on cardiac field, miRNAs are involved on cardiac hypertrophy regulation, both apoptosis and fibroses process, and some ones are able to determined endothelial functionality as well as vessel growth [119].

miRNAs have a role on pluripotency control [120], selfrenewal and ESC differentiation [121]. It have also been described the miRNAs involvement in controlling adult stem cells and progenitors, as they can regulate cardiac progenitor cell and myoblasts proliferation [122]. Postnatal switches in CMCs proliferation and regenerative capacity coincide with changes of the expression of cell cycle regulator genes, and a recent study suggested the role of microRNAs (miRNAs) in this regulation $[123,124]$. miRNAS are also able to induce ckit+CSC differentiation. Concretely, the main miRNAs implicated in cardiac differentiation are miR-1, miR-133, miR-208 and miR-499, known as a "myomiRNAs" [125]. They could be used as potent tools for increasing cardiac differentiation. Several groups have reported how the control of miRNAs may regulate the heart physiology. Besides, the combined expression of specific miRNAs enhanced the therapeutic efficacy for treatment of ischemic heart diseases, because their overexpression improve the engraftment of transplanted CSC [126].

It has been also shown that miRNAs can promote reprogramming of human fibroblasts [127]. miRNAs have also a role on cell reprogramming mouse fibroblast into CMC-like cell both in vitro and in vivo [128]. Recently, it has been explore the possibility of adult fibroblast can be reprogrammed into $\mathrm{CMC}$-like expressing specific cardiac transcription factors and muscle specific miRNAs, showing finally reprogrammed cells expressing several cardiac markers, down-expressing non-myocyte markers, showing the typically sarcomera-like structures and reporting that small reprogrammed cell subset present spontaneous beating [33].

Moreover, stem cells can secret exosomes, the $40-100 \mathrm{~nm}$ size membrane vesicles containing miRNA [129]. Increasing evidence suggested that exosomes play an important role for miRNA communication between donor cells and recipient tissues [130], and exosomes mediated paracrine effect might be a novel mechanism for beneficial effect of CPC transplantation. Exosomes from BMSCs have been reported to reduce myocardial $\mathrm{I} / \mathrm{R}$ injury ex vivo [3].

The administration of purified CPC exosomes can efficiently protects CMCs from oxidative induced apoptosis in vitro and acute myocardial apoptosis in mouse models of acute MI [3]. For myocardium with acute I/R injury, myocardial injury is potential reversible if treated with cardioprotective exosomes early during the critical time window [131].

\section{Homing/Migration}

Very often the new cells that replace the dead ones migrate from specific niches within the tissue or from distant environments such as the bone marrow [132]. Different mechanisms have been used to increase the migration and homing of stem cells. In fact, the use of cytokines and surface molecules has been extensively studied during recent years [132-134].

As instance, it has been shown that cardiac mesoangioblasts restore to a significant extent heart structure and function in mouse model of CAL [47]. However, the partial effect observed in this model was attributed to the limiting homing of these cardiac mesoangioblasts to the heart, likely due to their retention in filter organs [47]. To increase the efficiency of cardiac repair 


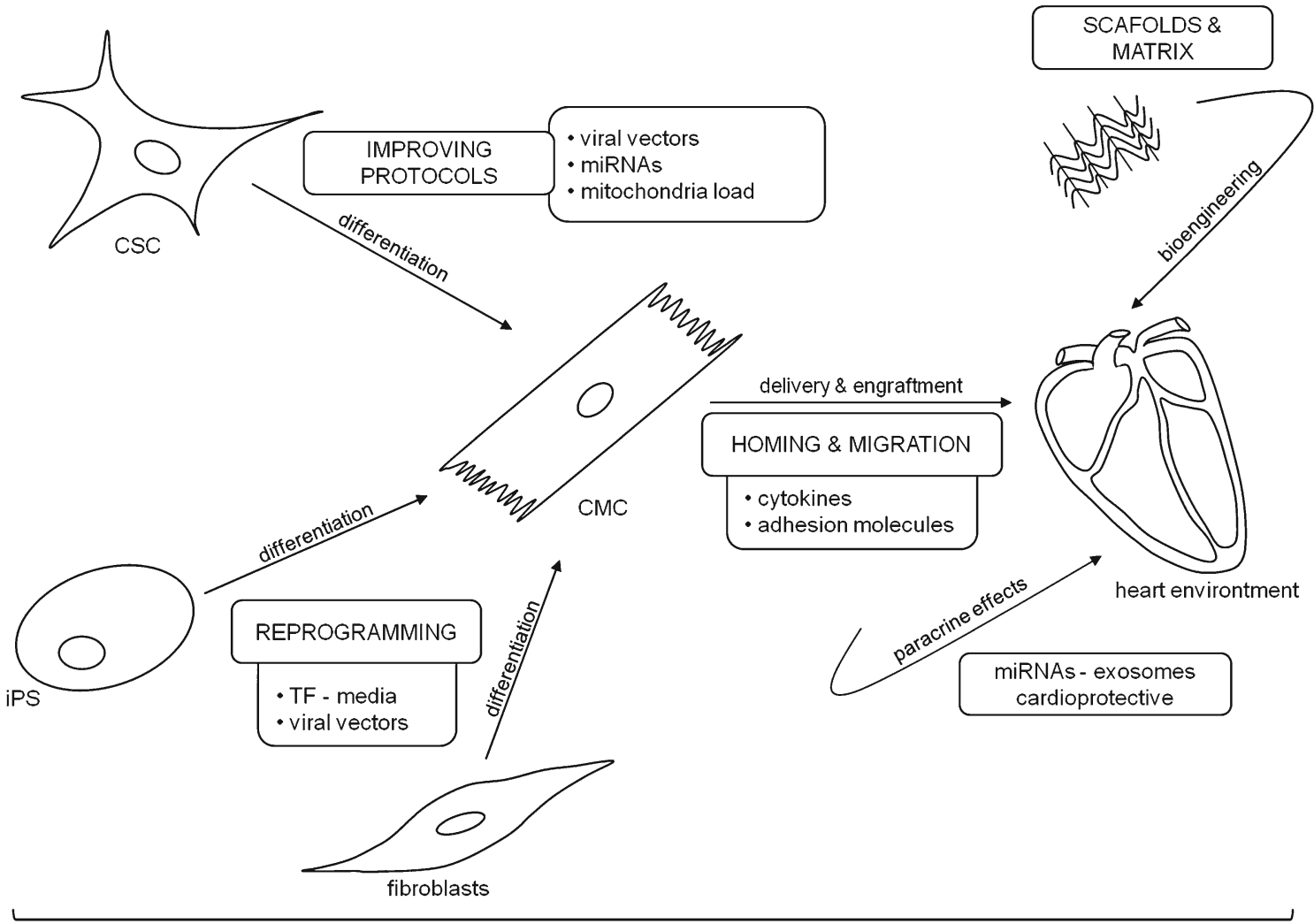

Mechanisms to enhance cardiac cell therapy

Fig. 1 Mechanisms to enhance cardiac cell therapy

by cardiac mesoangioblasts it would be necessary to increase their homing and survival in the heart, with the additional benefit of reducing unspecific trapping in the capillary filters of the body. It has been recently reported that the expression of L-selectin together with the exposure of cells to SDF-1 improved the homing of cardiac mesoangioblasts to the infarcted free wall of the heart; it has also been reported that this treatment improved the recovery of the left ventricular wall motion after infarction and the quantity of regenerated myocardium [133].

\section{Improving Differentiation Protocols}

It seems a rare and difficult task for differentiated cells to switch a determined lineage under natural conditions. However, accumulative evidence demonstrates that experimental manipulations can overcome this hurdle. Recent findings indicate that forced expression of fate-determining transcription factors can eventually wrest control of the developmental program of a cell type that has previously been committed to a specific lineage [1].

Different kinds of strategies have been explored to enhance cell differentiation capacity. Not only the cellular coculture in presence of neonatal CMCs but also it has been extensively used the chemical treatment by 5 'azacitidine, which is a drug that induces cardiac transcription factor expression, promoting cell differentiation.

Besides, different pharmacological drugs have been described to enhance organ regeneration and tissue repair or to decrease inflammation produced after injury as well as to promote angiogenesis. For example, the $\beta$-blockers can increase the myocardial load and to promote de neurohormonal activation in patients after MI [135].

Moreover, gene therapy allows promote cardiac differentiation through overexpressing the specific cardiac markers as well as down-regulating the "stem-ones" using a viral vectors [33]. Besides, it is possible to influence on cellular gene profile through miRNAs o by reprogramming technology. To increase the therapeutic potency of mesenchymal stem cells, they have been genetically modified to overexpress not only the typical cardiac transcription factors, but also pro-survival factors, angiogenic factors, growth factors, or stem-cell homing factors [136].

Surprisingly, it has also been attributed a key-role of mitochondria in cardiac differentiation. Recently, two cardiac stem cells clones with different cardiogenic potential have been reported to differ mainly in the mitochondrial load. Slowly dividing clones showing a higher quantity of mitochondria responded efficiently to 5'azacytidine chemical treatment reaching mature cardiac cell differentiation; in 
contrast, the other cardiac clones subset, which showed fast dividing turn-over but with lower mitochondrial quantity, did not respond to chemical differentiation treatment [114]. Therefore, mitochondrial load could be also a tool to further develop on cardiac cell therapy.

\section{Matrix/Scaffolds}

It has also been explored the tissue bioengineer possibilities as an alternative or complementary strategy on cardiac cell therapy. Biomaterials have been used for in situ cardiac tissue engineering both as an alone acellular solution and as a hybrid therapy combined with cell or other therapeutic strategies. Biomaterials can be used in situ to increase wall thickness, to restore the heart geometry, and to provide support of an injured left ventricle [137]. Much research effort has been focused on naturally occurring polymers such as collagen and chitosan [138].

Biomaterials-based expansion and lineage specific differentiation has been achieved with murine ESCs and MSCs [139].

Besides, scaffold-free hESC-derived cardiac patches have been demonstrated to be successful, along synthetic polymers, hydrogels as well as other natural polymers such as fibrin or collagen I [138].

The use of three-dimensional (3D) cultures may induce cardiac progenitor cells to synthesize their own extracellular matrix (ECM) and sarcomeric proteins to initiate cardiac differentiation. 3D cultures grown on synthetic scaffolds may favour the implantation and survival of stem cells for cell therapy when pharmacological therapies are not efficient in curing cardiovascular diseases and when organ transplantation remains the only treatment able to rescue the patient's life. Silk fibroin-based scaffolds may be used to increase cell affinity to biomaterials and may be chemically modified to improve cell adhesion. From that, it has been studied a porous, partially orientated and electrospun nanometric nets, where cardiac progenitor cells isolated from adult rats were seeded by capillarity in the 3D structures and cultured inside inserts for 21 days. It has been report that these cells expressed a high level of sarcomeric and cardiac proteins and synthesized a great quantity of ECM. Specifically, partially orientated scaffolds induced the synthesis of titin, which is a fundamental protein in sarcomere assembly [140].

Tissue-engineered heart valves (TEHV) have been proposed as a promising solution for the clinical needs of pediatric patients. In vivo studies have shown TEHV leaflet contraction and regurgitation after several months of implantation. It has been developed a mature ECM in a fibrin-based scaffold that generates commissural alignment in TEHV leaflets and then removed these cells using detergents [141].
Induced pluripotent stem cell (iPS) iPS cells, like ES cells, are also a highly attractive tool [31,32], As it has been already shown with notable examples is the derivation of iPS cells from adult somatic cells[31]. iPS cells were established by overexpression of four reprogramming transcription factors (Oct3/4, Sox2, Klf4 and c-Myc) in fibroblasts [32]. Relevant to cardiac cells, direct differentiation of non-cardiogenic mesoderm [142], of ES cells [143] and reprogramming of cardiac or dermal fibroblast [144] into beating CMCs have been demonstrated and is becoming efficient. iPS cells contributed to the formation of all cardiovascular lineages and their implantation supposed a recovery improvement after MI [145].

A new proposal on cardiac field related on reprogramming technology is to develop de novo CMC as a potential alternative source by "direct reprogramming of murine cardiac fibroblast and other kind of adult cells to CMC by through typically cardiac transcription factors such as GATA4, Mef2c and Tbx 5 [144]. This approach allow cardiac fibroblast reprogramming to be used for in vivo regeneration using these transcription factor by their direct delivery [146]. Reprogramming fibroblast into CMC modification methods has been proposed using exogenous expression of pluripotency genes (Oct4, Sox2 and Klf4) to be differentiated into a cardiac cell lineage [147].

Yet, an ideal scenario would involve targeted reprogramming of an abundant resident source in the heart, one that could transdifferentiate to the myocardial lineage with minimal steps [1]. Although the underlying mechanisms remain understood and their safety is still an opened question due to retroviral gene transfer, reprogramming is an exciting methodology for generating patient-derived $\mathrm{CMCs}$.

\section{Cardiac Cell Therapy on Clinical Trials}

Several stem cell populations, such as ckit + cells [148] and bone marrow mononucleated cells [149, 150], have been subjects of clinical trials in patients with heart disease.

Although several types include somatic stem cell from adult tissues have been used to reconstitute myocardium [151], BMSC have been the most widely used and recently tested in clinical trials $[152,153]$. There has been a flurry of reports of human myocardial therapy using BMSCs [154, 155] based, in part, on early results with myocardial regeneration with the BMSC [35].

Clinical studies suggest that cell-based therapy with EPCs can improve myocardial function. So far, most clinical studies have used bone-marrow mononuclear cells and showed either no benefit or small, but possibly clinically important, improvements in cardiac function. The mechanisms of these functional improvements are unknown, but it is unlikely that the improvements result from differentiation of the injected 
cells into CMCs. Growth factor and cytokine release by injected cells is frequently suggested as a potential mechanism of action [156], and improved microvascular function has been shown in the REPAIR-AMI study [157]. In clinical trials, transplantation of non-cardiac stem cells such as skeletal muscle progenitor and BMSC has results in minor improvement in left ventricle ejection fraction, but it has been also shown that induce arrhythmias [158].

The modest effects of clinical studies using intracoronary administration of autologous bone marrow-derived mononuclear cells (BMMCs) in patients with chronic post-infarction heart failure may be attributed to impaired homing of BMMCs to the target area [149]. Extracorporeal shock wave treatment has been experimentally shown to increase homing factors in the target tissue, resulting in enhanced retention of applied BMMCs [159]. Shock wave tissue pretreatment facilitated intracoronary administration of BMCs result in a regional wall thickening improvement as it has been reported on the CELLWAVE clinical trial. Determining whether the increase in contractile function will translate into improved clinical outcomes requires confirmation in larger clinical end point trials [149].

The catheter based intra-myocardial stem cells delivery is another important administration system that has been developed in recent years [160]. This system has been demonstrated to be more efficient and safe in clinical trials, increasing the engraftment rate in cell therapies.

Cardiopoietic stem cell therapy improves left ventricular function and blunts pathological remodeling. C-Cure clinical trial focus on evaluate the feasibility and safety of autologous BMSC and cardiogenically-oriented mesenchymal stem cell therapy, and probe for efficacy signals in patients with chronic heart failure has shown the left ventricular ejection fraction was improved by cell therapy [161].

Regarding ckit $+\mathrm{CSC} /$ resident cardiac precursors, they offer an alternative or complementary therapeutic approach to harness the endogenous regenerative potential without exogenous delivery of stem cells [112]. The extraordinary clinical potential of myocardial repair makes the dissection of the biology of the CSC a challenging and exciting endeavor [16]. It is intuitively apparent that resident CSCs are the preferential cells to be tested for cardiac repair, not only due to these cells are programmed to make myocytes and vascular structures but also due to this cell population suppose an endogenous cell source that is one of the major goals in regenerative medicine $[6,17]$.

SCIPIO clinical trial [148] study the use of autologous CSCs for the treatment of heart failure resulting from ischaemic heart disease. The phase I showed an increase of LVEF as well as a decrease of infarct size at 4 month after infusion. Importantly, the salubrious effects of CSCs were even more pronounced at 1 year. SCIPIO outcome suggests that intracoronary infusion of autologous CSCs might be effective in improving LV systolic function and reducing infarct size in patients with heart failure after MI [148]. They have recently published the preliminary communication analyzing the myocardial function and viability by magnetic resonance [162].

In summary, enormous efforts have been made in the treatment of patients with cardiac diseases using stem cells therapies but now new important questions have been raised and bench work could be the better answer to improve strategies.

\section{Prospects of Myocardium Regeneration}

Therefore, although during the latest years our knowledge on cardiac stem cells biology and their properties have been tremendously improved, still the answer for improving the repair and regeneration of the heart has turned out uncompleted. It is required to join efforts back to the bench and try to understand further the mechanistic properties of the cardiac cells as well as the heart tissue structure and function. To note that important concepts can be extrapolated from the cardiac development studies, without forgetting that it is possible that cardiogenesis and cardiac regeneration might result from distinct differentiation programs.

Acknowledgements This study was supported by grants from the Spanish Ministry of Science and Innovation (SAF 2010-15239) to BGG. BGG acknowledges support from the "Ramon y Cajal" tenure track programme from the Spanish Ministry of Science and Innovation (RYC2009-04669). The CNIC is supported by the Spanish Ministry of Science and Innovation and the Pro-CNIC Foundation. AB is supported by FPI fellowships from the Spanish Ministry.

Disclosure of potential conflicts of interest The authors indicate no potential conflicts of interest.

Open Access This article is distributed under the terms of the Creative Commons Attribution License which permits any use, distribution, and reproduction in any medium, provided the original author(s) and the source are credited.

\section{References}

1. Kikuchi, K., \& Poss, K. D. (2012). Cardiac regenerative capacity and mechanisms. Annual Review of Cell and Developmental Biology, 28, 719-741.

2. Oh, H., Bradfute, S. B., Gallardo, T. D., Nakamura, T., Gaussin, V., et al. (2003). Cardiac progenitor cells from adult myocardium: homing, differentiation, and fusion after infacrtion. Proc Nat Acad Sci, 100, 12313-12318.

3. Chen, L., Wang, Y., Pan, Y., Zhang, L., Shen, C., et al. (2013). Cardiac progenitor-derived exosomes protect ischemic myocardium from acute ischemia/reperfusion injury. Biochemical and Biophysical Research Communications, 431, 566-571.

4. Huang, C., Gu, H., Yu, Q., Manukyan, M. C., Poynter, J. A., et al. (2011). Sca-1+ cardiac stem cells mediate acute cardioprotection 
via paracrine factor SDF-1 following myocardial ischemia/reperfusion. PloS One, 6

5. Laugwitz, K. L., Moretti, A., Lam, J., Gruber, P., Chen, Y., et al. (2005). Postnatal isl1+ cardioblasts enter fully differentiated cardiomyocyte lineages. Nature, 433, 647-653.

6. Linke, A., Müller, P., Nurzynska, D., Casarsa, C., Torella, D., et al. (2005). Stem cells in the dog heart are self-renewing, clonogenic, and multipotent and regenerate infarcted myocardium, improving cardiac function. Proceedings of the National Academy of Sciences of the United States of America, 102, 8966-8871.

7. Messina, E., De Angelis, L., Frati, G., Morrone, S., Chimenti, S., et al. (2004). Isolation and and expansion of adult cardiac stem cells from human and murine heart. Circulation Research, 95, 911-921.

8. Itescu, S., Schuster, M. D., \& Kocher, A. A. (2003). New directions in strategies using cell therapy for heart disease. $J \mathrm{Mol} \mathrm{Med}$ (Berl), 81, 288-296.

9. Kikuchi, K., Holdway, J. E., Major, R. J., Blum, N., Dahn, R. D., et al. (2011). Retinoic acid production by endocardium and epicardium is an injury response essential for zebrafish heart regeneration. Developmental Cell, 20(3), 397-404.

10. Lepilina, A., Coon, A. N., Kikuchi, K., Holdway, J. E., Roberts, R. W., et al. (2006). A dynamic epicardial injury response supports progenitor cell activity during zebrafish heart regeneration. Cell, 127, 607-619.

11. Kikuchi, K., Holdway, J. E., Werdich, A. A., Anderson, R. M., Fang, Y., et al. (2010). Primary contribution to zebrafish heart regeneration by gata4(+) cardiomyocytes. Nature, 464, 601-605.

12. MacLellan, W. R., \& Schneider, M. D. (2000). Genetic dissection of cardiac growth control pathways. Annual Review of Physiology, 62, 289-319.

13. Chien, K. R., \& Karsenty, G. (2005). Longevity and lineages: toward the integrative biology of degenerative diseases in heart, muscle, and bone. Cell, 120(4), 533-544.

14. Rumyantsev, P. P. (1977). Interrelations of the proliferation and differentiation processes during cardiact myogenesis and regeneration. International Review of Cytology, 51, 186-273.

15. Laflamme, M. A., \& Murry, C. E. (2011). Heart regeneration. Nature, 473, 326-335.

16. Anversa, P., Leri, A., \& Kajstura, J. (2006). Cardiac regeneration. Journal of the American College of Cardiology, 47, 1769-1776.

17. Beltrami, A. P., Barlucchi, L., Torella, D., Baker, M., Limana, F., et al. (2003). Adult cardiac stem cells are multipotent and support myocardial regeneration. Cell, 114, 763-776.

18. Urbanek, K., Cesselli, D., Rota, M., Nascimbene, A., De Angelis, A., et al. (2006). Stem cell niches in the adult mouse heart. Proceedings of the National Academy of Sciences of the United States of America, 103, 9226-9231.

19. Quaini, F., Urbanek, K., Beltrami, A. P., Finato, N., Beltrami, C. A., et al. (2002). Chimerism of the transplanted heart. The New England Journal of Medicine, 346, 5-15.

20. Kajstura, J., Urbanek, K., Perl, S., Hosoda, T., Zheng, H., et al. (2010). Cardiomyogenesis in the adult human heart. Circulation Research, 107, 305-315.

21. Oh, H., Taffet, G. E., Youker, K. A., Entman, M. L., Overbeek, P. A., et al. (2001). Telomerase reverse transcriptase promotes cardiac muscle cell proliferation, hypertrophy, and survival. Proceedings of the National Academy of Sciences of the United States of America, 98, 10308-10313.

22. Pasumarthi, K. B., Nakajima, H., Nakajima, H. O., Soonpaa, M. H., \& Field, L. J. (2005). Targeted expression of cyclin D2 results in cardiomyocyte DNA synthesis and infarct regression in transgenic mice. Circulation Research, 96, 110-118.

23. Limana, F., Urbanek, K., Chimenti, S., Quaini, F., Leri, A., et al. (2002). bcl-2 overexpression promotes myocyte proliferation. Proceedings of the National Academy of Sciences of the United States of America, 99, 6257-6262.
24. Liao, H. S., Kang, P. M., Nagashima, H., Yamasaki, N., Usheva, A., et al. (2001). Cardiac-specific overexpression of cyclin-dependent kinase 2 increases smaller mononuclear cardiomyocytes. Circulation Research, 88, 443-450.

25. Chien, K. R. (2004). Stem cells: lost in translation. Nature, 428(6983), 607-608.

26. Di Trapani, M., Bassi, G., Ricciardi, M., Fontana, E., Bifari, F., et al. (2013). Comparative study of immune regulatory properties of stem cells derived from different tissues. Stem cells and development.

27. Thomson, J. A., Itskovitz-Eldor, J., Shapiro, S. S., Waknitz, M. A., Swiergiel, J. J., et al. (1998). Embryonic stem cell lines derived from human blastocysts. Science, 282, 1145-1147.

28. Garry, D. J., \& Olson, E. N. (2006). A common progenitor at the heart of development. Cell, 127, 1101-1104.

29. Nussbaum, J., Minami, E., Laflamme, M. A., Virag, J. A., Ware, C. B., et al. (2007). Transplantation of undifferentiated murine embryonic stem cells in the heart: teratoma formation and immune response. The FASEB Journal, 21, 1345-1357.

30. Behfar, A., Perez-Terzic, C., Faustino, R. S., Arrell, D. K., Hodgson, D. M., et al. (2007). Cardiopoietic programming of embryonic stem cells for tumor-free heart repair. The Journal of Experimental Medicine, 204, 405-420.

31. Takahashi, K., \& Yamanaka, S. (2006). nduction of pluripotent stem cells from mouse embryonic and adult fibroblast cultures by defined factors. Cell, 126, 663-676.

32. Takahashi, K., Tanabe, K., Ohnuki, M., Narita, M., Ichisaka, T., et al. (2007). Induction of pluripotent stem cells from adult human fibroblasts by defined factors. Cell, 131(5), 861-872.

33. Nam, Y. J., Song, K., Luo, X., Daniel, E., Lambeth, K., et al. (2013). Reprogramming of human fibroblasts toward a cardiac fate. Proceedings of the National Academy of Sciences of the United States of America, 11, 5588-5593.

34. Li, M., \& Ikehara, S. (2013). Bone-marrow-derived mesenchymal stem cells for organ repair. Stem Cells Int, 2013, 132642.

35. Orlic, D., Kajstura, J., Chimenti, S., Jakoniuk, I., Anderson, S. M., et al. (2001). Bone marrow cells regenerate infarcted myocardium. Nature, 410, 701-705.

36. Toma, C., Pittenger, M. F., Cahill, K. S., Byrne, B. J., \& Kessler, P. D. (2002). Human mesenchymal stem cells differentiate to a cardiomyocyte phenotype in the adult murine heart. Circulation, 105, 93-98.

37. Orlic, D., Kajstura, J., Chimenti, S., Limana, F., Jakoniuk, I., et al. (2001). Mobilized bone marrow cells repair the infarcted heart, improving function and survival. Proceedings of the National Academy of Sciences of the United States of America, 98, 10344-10349.

38. Yoon, Y. S., Wecker, A., Heyd, L., Park, J. S., Tkebuchava, T., et al. (2005). Clonally expanded novel multipotent stem cells from human bone marrow regenerate myocardium after myocardial infarction. The Journal of Clinical Investigation, 115, 326-338.

39. Kajstura, J., Rota, M., Whang, B., Cascapera, S., Hosoda, T., et al. (2005). Bone marrow cells differentiate in cardiac cell lineages after infarction independently of cell fusion. Circulation Research, 96, 127-137.

40. Mirotsou, M., Zhang, Z., Deb, A., Zhang, L., Gnecchi, M., et al. (2007). Secreted frizzled related protein 2 (Sfrp2) is the key Aktmesenchymal stem cell-released paracrine factor mediating myocardial survival and repair. Proceedings of the National Academy of Sciences of the United States of America, 104, 1643-1648.

41. Wang, M., Tan, J., Wang, Y., Meldrum, K. K., Dinarello, C. A., et al. (2009). IL-18 binding protein-expressing mesenchymal stem cells improve myocardial protection after ischemia or infarction. Proceedings of the National Academy of Sciences of the United States of America, 106, 17499-17504.

42. Uemura, R., Xu, M., Ahmad, N., \& Ashraf, M. (2006). Bone marrow stem cells prevent left ventricular remodeling of ischemic 
heart through paracrine signaling. Circulation Research, 98, 1414-1421.

43. Bergmann, O., Bhardwaj, R. D., Bernard, S., Zdunek, S., Barnabé-Heider, F., et al. (2009). Evidence for cardiomyocyte renewal in humans. Science, 324, 98-102.

44. He, J. Q., Vu, D. M., Hunt, G., Chugh, A., Bhatnagar, A., et al. (2011). Human cardiac stem cells isolated from atrial appendages stably express c-kit. PloS One, 6(11), e27719. doi:101371/ journalpone0027719 E 6.

45. Towbin, J. A., \& Bowles, N. E. (2002). The failing heart. Nature, 415, 227-233.

46. Gálvez, B. G., Covarello, D., Tolorenzi, R., Brunelli, S., Dellavalle, A., et al. (2009). Human cardiac mesoangioblasts isolated from hypertrophic cardiomyopathies are greatly reduced in proliferation and differentiation potency. Cardiovascular Research, 83, 707-716.

47. Galvez, B. G., Sampaolesi, M., Barbuti, A., Crespi, A., Covarello, D., et al. (2008). Cardiac mesoangioblasts are committed, selfrenewable progenitors, associated with small vessels of juvenile mouse ventricle. Cell Death and Differentiation, 15, 1417-1428.

48. Matsuura, K., Nagai, T., Nishigaki, N., Oyama, T., Nishi, J., et al. (2004). Adult cardiac Sca-1-positive cells differentiate into beating cardiomyocytes. The Journal of Biological Chemistry, 279, 11384-11391.

49. Smits, A. M., van Laake, L. W., den Ouden, K., Schreurs, C., Szuhai, K., et al. (2009). Human cardiomyocyte progenitor cell transplantation preserves long-term function of the infarcted mouse myocardium. Cardiovascular Research, 83, 527-535.

50. Vanelli, A., Pennarossa, G., Maffei, S., Galvez, B. G., Cossu, G., et al. (2012). Isolation, characterization and differentiation potential of cardiac progenitor cells in adult pigs. Stem Cell Reviews, 8, 706-719.

51. Martin, C. M., Meeson, A. P., Robertson, S. M., Hawke, T. J., Richardson, J. A., et al. (2004). Persistent expression of the ATPbinding cassette transporter, Abcg2, identifies cardiac SP cells in the developing and adult heart. Developmental Biology, 265, 262-275.

52. Pfister, O., Mouquet, F., Jain, M., Summer, R., Helmes, M., et al. (2005). CD31- but Not CD31+ cardiac side population cells exhibit functional cardiomyogenic differentiation. Circulation Research, 97, 52-61.

53. Matsuura, K., Yoshioka, S., Tosha, T., Hori, H., Ishimori, K., et al. (2005). Structural diversities of active site in clinical azole-bound forms between sterol 14alpha-demethylases (CYP51s) from human and Mycobacterium tuberculosis. The Journal of Biological Chemistry, 280, 9088-9096.

54. Bearzi, C., Rota, M., Hosoda, T., Tillmanns, J., Nascimbene, A., et al. (2007). Human cardiac stem cells. Proc Natl Acad Sci USA, 104(35), 14068-73.

55. Bu, L., Jiang, X., Martin-Puig, S., Caron, L., Zhu, S., et al. (2009). Human ISL1 heart progenitors generate diverse multipotent cardiovascular cell lineages. Nature, 460, 113-117.

56. Pfister, O., Oikonomopoulos, A., Sereti, K. I., \& Liao, R. (2010). Isolation of resident cardiac progenitor cells by Hoechst 33342 staining. Methods in Molecular Biology, 660, 53-63.

57. Hierlihy, A. M., Seale, P., Lobe, C. G., Rudnicki, M. A., \& Megeney, L. A. (2002). The post-natal heart contains a myocardial stem cell population. FEBS Letters, 530, 239-243.

58. Smith, R. R., Barile, L., Cho, H. C., Leppo, M. K., Hare, J. M., et al. (2007). Regenerative potential of cardiosphere-derived cells expanded from percutaneous endomyocardial biopsy specimens. Circulation, 115, 896-908.

59. Cai, C. L., Martin, J. C., Sun, Y., Cui, L., Wang, L., et al. (2008). A myocardial lineage derives from Tbx18 epicardial cells. Nature, 454, 104-108.

60. Castaldo, C., Di Meglio, F., Nurzynska, D., Romano, G., Maiello, C., et al. (2008). CD117-positive cells in adult human heart are localized in the subepicardium, and their activation is associated with laminin-1 and alpha6 integrin expression. Stem Cells, 26, 1726-1731.

61. Barile, L., Chimenti, I., Gaetani, R., Forte, E., Miraldi, F., et al. (2007). Cardiac stem cells: isolation, expansion and experimental use for myocardial regeneration. Nature Clinical Practice. Cardiovascular Medicine, 4(Suppl 1), S9-S14.

62. Bolli, P., \& Chaudhry, H. W. (2010). Molecular physiology of cardiac regeneration. Annals of the New York Academy of Sciences, 1211, 113-126.

63. Bollini, S., Smart, N., \& Riley, P. R. (2011). Resident cardiac progenitor cells: at the heart of regeneration. Journal of Molecular and Cellular Cardiology, 50, 296-303.

64. Di Felice, V., Ardizzone, N. M., De Luca, A., Marciani, V., Marino Gammazza, A., et al. (2009). OPLA scaffold, collagen I, and horse serum induce a higher degree of myogenic differentiation of adult rat cardiac stem cells. Journal of Cellular Physiology, $221,729-739$.

65. Forte, G., Carotenuto, F., Pagliari, F., Pagliari, S., Cossa, P., et al. (2008). Criticality of biological and physical stimuli array inducing resident cardiac stem cell determination. Stem Cells, 26, 2093-2103.

66. Leri, A., Kajstura, J., \& Anversa, P. (2011). Role of cardiac stem cells in cardiac pathophysiology: a paradigm shift in human myocardial biology. Circulation Research, 109, 941-961.

67. Di Nardo, P., Forte, G., Ahluwalia, A., \& Minieri, M. (2010). Cardiac progenitor cells: potency and control. Journal of Cellular Physiology, 224, 590-600.

68. Di Felice, V., De Luca, A., Colorito, M. L., Montalbano, A., Ardizzone, N. M., et al. (2009). Cardiac stem cell research: an elephant in the room? The Anatomical Record, 292, 449-454.

69. Ellison, G. M., Galuppo, V., Vicinanza, C., Aquila, I., Waring, C. D., et al. (2010). Cardiac stem and progenitor cell identification: different markers for the same cell? Frontiers in Bioscience (Scholar Edition), 2, 641-652.

70. Ellison, G. M., Torella, D., Karakikes, I., \& Nadal-Ginard, B. (2007). Myocyte death and renewal: modern concepts of cardiac cellular homeostasis. Nature Clinical Practice. Cardiovascular Medicine, 3(Suppl 1), S8-13.

71. Bearzi, C., Leri, A., Lo Monaco, F., Rota, M., Gonzalez, A., et al. (2009). Identification of a coronary vascular progenitor cell in the human heart. Proceedings of the National Academy of Sciences of the United States of America, 106, 15885-15890.

72. Potten, C. S., \& Loeffler, M. (1990). Stem cells: attributes, cycles, spirals, pitfalls and uncertainties. Lessons for and from the crypt. Development, 110, 1001-1020.

73. Mishra, R., Vijayan, K., Colletti, E. J., Harrington, D. A., Matthiesen, T. S., et al. (2011). Characterization and functionality of cardiac progenitor cells in congenital heart patients. Circulation, 123, 364-373.

74. Itzhaki-Alfia, A., Leor, J., Raanani, E., Sternik, L., Spiegelstein, D., et al. (2009). Patient characteristics and cell source determine the number of isolated human cardiac progenitor cells. Circulation, 120, 2559-2566.

75. Sandstedt, J., Jonsson, M., Lindahl, A., Jeppsson, A., \& Asp, J. (2010). C-kit+CD45- cells found in the adult human heart represent a population of endothelial progenitor cells. Basic Research in Cardiology, 105, 545-556.

76. Kuhn, E. N., \& Wu, S. M. (2010). Origin of cardiac progenitor cells in the developing and postnatal heart. Journal of Cellular Physiology, 225, 321-325.

77. Zhou, Y., Pan, P., Yao, L., Su, M., He, P., et al. (2010). CD117positive cells of the heart: progenitor cells or mast cells? The Journal of Histochemistry and Cytochemistry, 58, 309-316.

78. D'Amario, D., Fiorini, C., Campbell, P. M., Goichberg, P., Sanada, F., et al. (2011). Functionally competent cardiac stem cells can be isolated from endomyocardial biopsies of patients with advanced 
cardiomyopathies. Circulation Research, 108(7), 857-61. doi:101161/CIRC.

79. Rota, M., LeCapitaine, N., Hosoda, T., Boni, A., De Angelis, A., et al. (2006). Diabetes promotes cardiac stem cell aging and heart failure, which are prevented by deletion of the p66shc gene. Circulation Research, 99(1), 42-52.

80. Hong, K. U., Li, Q. H., Guo, Y., Patton, N. S., Moktar, A., et al. (2013). A highly sensitive and accurate method to quantify absolute numbers of c-kit + cardiac stem cells following transplantation in mice. Basic Research in Cardiology, 108, 346.

81. Nelson, T. J., Faustino, R. S., Chiriac, A., Crespo-Diaz, R., Behfar, A., et al. (2008). CXCR4+/FLK-1+ biomarkers select a cardiopoietic lineage from embryonic stem cells. Stem Cells, 26, 1464-1473.

82. Xiao, J., Liang, D., Zhang, H., Liu, Y., Zhang, D., et al. (2012). MicroRNA-204 is required for differentiation of human-derived cardiomyocyte progenitor cells. Journal of Molecular and Cellular Cardiology, 53, 751-759.

83. Moretti, A., Caron, L., Nakano, A., Lam, J. T., Bernshausen, A., et al. (2006). Multipotent embryonic isl1+ progenitor cells lead to cardiac, smooth muscle, and endothelial cell diversification. Cell, 127,1151 .

84. Cai, C. L., Liang, X., Shi, Y., Chu, P. H., Pfaff, S. L., et al. (2003). Isl1 identifies a cardiac progenitor population that proliferates prior to differentiation and contributes a majority of cells to the heart. Developmental Cell, 5, 877-889.

85. Dodou, E., Verzi, M. P., Anderson, J. P., Xu, S. M., \& Black, B. L. (2004). Mef2c is a direct transcriptional target of ISL1 and GATA factors in the anterior heart field during mouse embryonic development. Development, 131, 3931-3942.

86. Leri, A. (2009). Human cardiac stem cells: the heart of a truth. Circulation, 120, 2515-2518.

87. Minasi, M. G., Riminucci, M., De Angelis, L., Borello, U., Berarducci, B., et al. (2002). The meso-angioblast: a multipotent, self-renewing cell that originates from the dorsal aorta and differentiates into most mesodermal tissues. Development, 129, 2773-2783.

88. Berry, S. E., Liu, J., Chaney, E. J., \& Kaufman, S. J. (2007). Multipotential mesoangioblast stem cell therapy in the mdx/utrn-/mouse model for Duchenne muscular dystrophy. Regenerative Medicine, 2, 275-288.

89. Morosetti, R., Mirabella, M., Gliubizzi, C., Broccolini, A., Sancricca, C., et al. (2007). Isolation and characterization of mesoangioblasts from facioscapulohumeral muscular dystrophy muscle biopsies. Stem Cells, 25, 3173-3182.

90. Sampaolesi, M., Blot, S., D'Antona, G., Granger, N., Tonlorenzi, R., et al. (2006). Mesoangioblast stem cells ameliorate muscle function in dystrophic dogs. Nature, 444, 574-579.

91. Wang, L., Kamath, A., Frye, J., Iwamoto, G. A., Chun, J. L., et al. (2012). Aorta-derived mesoangioblasts differentiate into the oligodendrocytes by inhibition of the Rho kinase signaling pathway. Stem Cells and Development, 21, 1069-1089.

92. Nees, S., Weiss, D. R., \& Juchem, G. (2013). Focus on cardiac pericytes. Pflügers Archiv, 465, 779-787.

93. Matsuura, K., Honda, A., Nagai, T., Fukushima, N., Iwanaga, K., et al. (2009). Transplantation of cardiac progenitor cells ameliorates cardiac dysfunction after myocardial infarction in mice. The Journal of Clinical Investigation, 119, 2204-2217.

94. Lee, T. H., D'Asti, E., Magnus, N., Al-Nedawi, K., Meehan, B., et al. (2011). Microvesicles as mediators of intercellular communication in cancer-the emerging science of cellular 'debris'. Seminars in Immunopathology, 33, 455-467.

95. Martin-Puig, S., Wang, Z., \& Chien, K. R. (2008). Lives of a heart cell: tracing the origins of cardiac progenitors. Cell Stem Cell, 2, 320-331.

96. Pfister, O., Oikonomopoulos, A., Sereti, K. I., Sohn, R. L., Cullen, D., et al. (2008). Role of the ATP-binding cassette transporter
Abcg2 in the phenotype and function of cardiac side population cells. Circulation Research, 103, 825-835.

97. Ishii, Y., Garriock, R. J., Navetta, A. M., Coughlin, L. E., \& Mikawa, T. (2010). BMP signals promote proepicardial protrusion necessary for recruitment of coronary vessel and epicardial progenitors to the heart. Developmental Cell, 19, 307-316.

98. Zhou, B., Ma, Q., Rajagopal, S., Wu, S. M., Domian, I., et al. (2008). Epicardial progenitors contribute to the cardiomyocyte lineage in the developing heart. Nature, 454, 109-113.

99. Martínez-Estrada, O. M., Lettice, L. A., Essafi, A., Guadix, J. A., Slight, J., et al. (2010). Wt1 is required for cardiovascular progenitor cell formation through transcriptional control of Snail and Ecadherin. Nature Genetics, 42, 89-93.

100. Zhou, B., Honor, L. B., He, H., Ma, Q., Oh, J. H., et al. (2011). Adult mouse epicardium modulates myocardial injury by secreting paracrine factors. The Journal of Clinical Investigation, 121, 1894-1904.

101. Limana, F., Zacheo, A., Mocini, D., Mangoni, A., Borsellino, G., et al. (2007). Identification of myocardial and vascular precursor cells in human and mouse epicardium. Circulation Research, 101, $1255-1265$.

102. Wang, J., Panáková, D., Kikuchi, K., Holdway, J. E., Gemberling, M., et al. (2011). The regenerative capacity of zebrafish reverses cardiac failure caused by genetic cardiomyocyte depletion. Development, 138, 3421-3430.

103. Nadal-Ginard, B., Kajstura, J., Leri, A., \& Anversa, P. (2003). Myocyte death, growth, and regeneration in cardiac hypertrophy and failure. Circulation Research, 92, 139-150.

104. Saxena, A., Fish, J. E., White, M. D., Yu, S., Smyth, J. W., et al. (2008). Stromal cell-derived factor-1alpha is cardioprotective after myocardial infarction. Circulation, 117, 2224-2231.

105. Chimenti, I., Smith, R. R., Li, T. S., Gerstenblith, G., Messina, E., et al. (2010). Relative roles of direct regeneration versus paracrine effects of human cardiosphere-derived cells transplanted into infarcted mice. Circulation Research, 106(5), 971-80. doi:101161/CIRCRESA.

106. Miyamoto, S., Kawaguchi, N., Ellison, G. M., Matsuoka, R., Shin'oka, T., et al. (2010). Characterization of long-term cultured c-kit + cardiac stem cells derived from adult rat hearts. Stem Cells and Development, 19, 105-116.

107. Loffredo, F. S., Steinhauser, M. L., Gannon, J., \& Lee, R. T. (2011). Bone marrow-derived cell therapy stimulates endogenous cardiomyocyte progenitors and promotes cardiac repair. Cell Stem Cell, 8, 389-398.

108. Leri, A., Kajstura, J., \& Anversa, P. (2005). Cardiac stem cells and mechanisms of myocardial regeneration. Physiological Reviews, $85,1373-1416$

109. Jackson, K. A., Majka, S. M., Wang, H., Pocius, J., Hartley, C. J., et al. (2001). Regeneration of ischemic cardiac muscle and vascular endothelium by adult stem cells. The Journal of Clinical Investigation, 107, 1395-1402.

110. Wollert, K. C., \& Drexler, H. (2005). Clinical applications of stem cells for the heart. Circulation Research, 96, 151-163.

111. Amado, L. C., Saliaris, A. P., Schuleri, K. H., St John, M., Xie, J. S., et al. (2005). Cardiac repair with intramyocardial injection of allogeneic mesenchymal stem cells after myocardial infarction. Proc Natl Acad Sci USA, 102, 11474.

112. Segers, V. F., \& Lee, R. T. (2008). Stem-cell therapy for cardiac disease. Nature, 451, 937-942.

113. Tang, X. L., Rokosh, G., Sanganalmath, S. K., Yuan, F., Sato, H., et al. (2010). Intracoronary administration of cardiac progenitor cells alleviates left ventricular dysfunction in rats with a 30-dayold infarction. Circulation, 121, 293-305.

114. San Martin, N., Cervera, A. M., Cordova, C., Covarello, D., McCreath, K. J., et al. (2011). Mitochondria determine the differentiation potential of cardiac mesoangioblasts. Stem Cells, 29, 1064-1074. 
115. Latronico, M. V., \& Condorelli, G. (2009). MicroRNAs and cardiac pathology. Nature Reviews Cardiology, 6, 419-429.

116. Brett, J. O., Renault, V. M., Rafalski, V. A., Webb, A. E., \& Brunet, A. (2011). The microRNA cluster miR-106b 25 regulates adult neural stem/progenitor cell proliferation and neuronal differentiation. Aging (Albany NY), 3, 108-124.

117. Glass, C., \& Singla, D. K. (2011). ES cells overexpressing microRNA-1 attenuate apoptosis in the injured myocardium. Molecular and Cellular Biochemistry, 357, 135-141.

118. Juan, A. H., \& Sartorelli, V. (2010). MicroRNA-214 and polycomb group proteins: a regulatory circuit controlling differentiation and cell fate decisions. Cell Cycle, 9(8), 1445-6.

119. Bauersachs, J. (2010). Regulation of myocardial fibrosis by MicroRNAs. Journal of Cardiovascular Pharmacology, 56, 454- 459.

120. Wang, Y., Baskerville, S., Shenoy, A., Babiarz, J. E., Baehner, L., et al. (2008). Embryonic stem cell-specific microRNAs regulate the G1-S transition and promote rapid proliferation. Nature Genetics, 40, 1478-1483.

121. Martinez, N. J., \& Gregory, R. I. (2010). MicroRNA gene regulatory pathways in the establishment and maintenance of ESC identity. Cell Stem Cell, 7, 31-35.

122. Sluijter, J. P. G., van MIl, A., van Vliet, P., Metz, C. H. G., Liu, J., et al. (2010). MicroRna-1 and -499 regulate differentiation and proliferation in human-derived cardiomyocyte progenitor cells. ATVB, 30, 859-868.

123. Eulalio, A., Mano, M., Dal Ferro, M., Zentilin, L., Sinagra, G., et al. (2012). Funtional screening identifes miRNAs inducing cardiac regeneration. Nature, 492, 376-381.

124. Divakaran, V., \& Mann, D. L. (2008). The emerging role of microRNAs in cardiac remodeling and heart failure. Circulation Research, 103, 1072-1083.

125. Sluijter, J. P., van Mil, A., van Vliet, P., Metz, C. H., Liu, J., et al. (2010). MicroRNA-1 and -499 regulate differentiation and proliferation in human-derived cardiomyocyte progenitor cells. Arteriosclerosis, Thrombosis, and Vascular Biology, 30, 859-868.

126. Heinrich, E. M., \& Dimmeler, S. (2012). MicroRNAs and stem cells: control of pluripotency, reprogramming, and lineage commitment. Circulation Research, 110, 1014-1022.

127. Subramanyam, D., Lamouille, S., Judson, R. L., Liu, J. Y., Bucay, N., et al. (2011). Multiple targets of miR-302 and miR-372 promote reprogramming of human fibroblasts to induced pluripotent stem cells. Nature Biotechnology, 29, 443-448.

128. Jayawardena, T. M., Egemnazarov, B., Finch, E. A., Zhang, L., Payne, J. A., et al. (2012). MicroRNA-mediated in vitro and in vivo direct reprogramming of cardiac fibroblasts to cardiomyocytes. Circulation Research, 110, 1465-1473.

129. Biancone, L., Bruno, S., Deregibus, M. C., Tetta, C., \& Camussi, G. (2012). Therapeutic potential of mesenchymal stem cell-derived microvesicles. Nephrology, Dialysis, Transplantation, 27, 3037-3042.

130. Stoorvogel, W. (2012). Functional transfer of microRNA by exosomes. Blood, 119, 646-648.

131. Roubille, F., Franck-Miclo, A., Covinhes, A., Lafont, C., Cransac, F., et al. (2011). Delayed postconditioning in the mouse heart in vivo. Circulation, 124, 1330-1336.

132. Palumbo, R., Galvez, B. G., Pusterla, T., De Marchis, F., Cossu, G., et al. (2007). Cells migrating to sites of tissue damage in response to the danger signal HMGB1 require NF-kappaB activation. The Journal of Cell Biology, 179, 33-40.

133. Bernal, A., San Martín, N., Fernández, M., Covarello, D., Molla, F., et al. (2012). L-selectin and SDF-1 enhance the migration of mouse and human cardiac mesoangioblasts. Cell Death and Differentiation, 19, 345-355.

134. Galvez, B. G., Sampaolesi, M., Brunelli, S., Covarello, D., Gavina, M., et al. (2006). Complete repair of dystrophic skeletal muscle by mesoangioblasts with enhanced migration ability. The Journal of Cell Biology, 174, 231-243.
135. Frishman, W. H. (2013). $\beta$-Adrenergic Blockade in Cardiovascular Disease. Journal of Cardiovascular Pharmacology and Therapeutics.

136. Kral, B. G., \& Kraitchman, D. L. (2013). From Mice to Men: Gene Therapy's Future for Treatment of Myocardial Infarction. Circulation. Cardiovascular Imaging, 6, 360-362.

137. Christman, K. L., \& Lee, R. J. (2006). Biomaterials for the treatment of myocardial infarction. Journal of the American College of Cardiology, 48, 907-913.

138. Sreejit, P., \& Verma, R. S. (2013). Natural ECM as biomaterial for scaffold based cardiac regeneration using adult bone marrow derived stem cells. Stem Cell Reviews, 9, 158-171.

139. Chai, C., \& Leong, K. W. (2007). Biomaterials approach to expand and direct differentiation of stem cells. Molecular Therapy, 15, 467-480.

140. Di Felice, V., Serradifalco, C., Rizzuto, L., De Luca, A., Rappa, F., et al. (2013). Silk fibroin scaffolds enhance cell commitment of adult rat cardiac progenitor cells. Journal of Tissue Engineering and Regenerative Medicine.

141. Syedain, Z. H., Bradee, A. R., Kren, S., Taylor, D. A., \& Tranquillo, R. T. (2013). Decellularized tissue-engineered heart valve leaflets with recellularization potential. Tissue Engineering Part A, 19, 759-769.

142. Takeuchi, J. K., \& Bruneau, B. G. (2009). Directed transdifferentiation of mouse mesoderm to heart tissue by defined factors. Nature, 459, 708-711.

143. Kattman, S. J., Witty, A. D., Gagliardi, M., Dubois, N. C., Niapour, M., et al. (2011). Stage-specific optimization of activin/nodal and BMP signaling promotes cardiac differentiation of mouse and human pluripotent stem cell lines. Cell Stem Cell, 8, 228-240.

144. Ieda, M., Fu, J. D., Delgado-Olguin, P., Vedantham, V., Hayashi, Y., et al. (2010). Direct reprogramming of fibroblasts into functional cardiomyocytes by defined factors. Cell, 142, 375-386.

145. Sinnecker, D., Goedel, A., Laugwitz, K. L., \& Moretti, A. (2013). Induced pluripotent stem cell-derived cardiomyocytes: a versatile tool for arrhythmia research. Circulation Research, 1125, 961-968.

146. Burridge, P. W., Keller, G., Gold, J. D., \& Wu, J. C. (2012). Production of de novo cardiomyocytes: human pluripotent stem cell differentiation and direct reprogramming. Cell Stem Cell, 10, 16-28.

147. Efe, J. A., Yuan, X., Jiang, K., \& Ding, S. (2011). Development unchained: how cellular reprogramming is redefining our view of cell fate and identity. Science Progress, 94, 298-322.

148. Bolli, R., Chugh, A. R., D'Amario, D., Loughran, J. H., Stoddard, M. F., et al. (2011). Cardiac stem cells in patients with ischaemic cardiomyopathy (SCIPIO): initial results of a randomised phase 1 trial. Lancet, 378, 1847-1857.

149. Assmus, B., Walter, D. H., Seeger, F. H., Leistner, D. M., Steiner, J., et al. (2013). Effect of shock wave-facilitated intracoronary cell therapy on LVEF in patients with chronic heart failure: the CELLWAVE randomized clinical trial. Journal of the American Medical Association, 309, 1622-1631.

150. Janssens, S., Dubois, C., Bogaert, J., Theunissen, K., Deroose, C., et al. (2006). Autologous bone marrow-derived stem-cell transfer in patients with ST-segment elevation myocardial infarction: double-blind, randomised controlled trial. Lancet, 367, 113-121.

151. Beltrami, A. P., Cesselli, D., Bergamin, N., Marcon, P., Rigo, S., et al. (2007). Multipotent cells can be generated in vitro from several adult human organs (heart, liver, and bone marrow). Blood, 110, 3438-3446.

152. Britten, M. B., Abolmaali, N. D., Assmus, B., Lehmann, R., Honold, J., et al. (2003). Infarct remodeling after intracoronary progenitor cell treatment in patients with acute myocardial infarction (TOPCAREAMI): mechanistic insights from serial contrast-enhanced magnetic resonance imaging. Circulation, 108, 2212-2218.

153. Stamm, C., Westphal, B., Kleine, H. D., Petzsch, M., Kittner, C., et al. (2003). Autologous bone-marrow stem-cell transplantation for myocardial regeneration. Lancet, 361, 45-46. 
154. Perin, E. C., Dohmann, H. F., Borojevic, R., Silva, S. A., Sousa, A. L., et al. (2003). Transendocardial, autologous bone marrow cell transplantation for severe, chronic ischemic heart failure. Circulation, 107(18), 2294-302.

155. Tse, H. F., Kwong, Y. L., Chan, J. K., Lo, G., Ho, C. L., et al. (2003). Angiogenesis in ischaemic myocardium by intramyocardial autologous bone marrow mononuclear cell implantation. Lancet, 361(9351), 47-9.

156. Abdel-Latif, A., Bolli, R., Tleyjeh, I. M., Montori, V. M., Perin, E. C., et al. (2007). Adult bone marrow-derived cells for cardiac repair: a systematic review and meta-analysis. Archives of Internal Medicine, 167, 989-997.

157. Erbs, S., Linke, A., Schächinger, V., Assmus, B., Thiele, H., et al. (2007). Restoration of microvascular function in the infarct-related artery by intracoronary transplantation of bone marrow progenitor cells in patients with acute myocardial infarction: the Doppler Substudy of the Reinfusion of Enriched Progenitor Cells and Infarct Remodeling in Acute Myocardial Infarction (REPAIR-AMI) trial. Circulation, 116, 366-374.

158. Menasché, P. (2008). Cardiac cell therapy trials: chronic myocardial infarction and congestive heart failure. Journal of Cardiovascular Translational Research, 1, 201-206.
159. Aicher, A., Heeschen, C., Sasaki, K., Urbich, C., Zeiher, A. M., et al. (2006). Low-energy shock wave for enhancing recruitment of endothelial progenitor cells: a new modality to increase efficacy of cell therapy in chronic hind limb ischemia. Circulation, 114, 2823-2830.

160. Trachtenberg, B., Velazquez, D. L., Williams, A. R., McNiece, I., Fishman, J., et al. (2011). Rationale and design of the Transendocardial Injection of Autologous Human Cells (bone marrow and mesenchymal) in Chronic Ischemic Left Ventricular Dysfunction and Heart Failure Secondary to Myocardial Infarction (TAC-HFT) trial: A randomized, double-blind, placebo-controlled study of safety and efficacy. American Heart Journal, 161, 487-493.

161. Bartunek, J., Behfar, A., Dolatabadi, D., Vanderheyden, M., Ostojic, M., et al. (2013). Cardiopoietic stem cell therapy in heart failure The C-CURE multicenter randomized trial with lineagespecified biologics. Journal of the American College of Cardiology, S0735-1097, 01397-01391.

162. Chugh, A. R., Beache, G. M., Loughran, J. H., Mewton, N., Elmore, J. B., et al. (2012). Administration of cardiac stem cells in patients with ischemic cardiomyopathy: the SCIPIO trial: surgical aspects and interim analysis of myocardial function and viability by magnetic resonance. Circulation, 126, S54-64. 